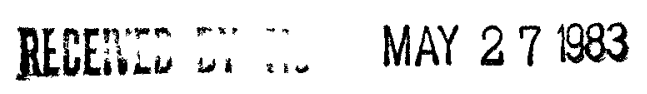

\title{
Comparison of CRBR Design Basis Events with Those of Foreign LMFBR Plants
}

Prepared by A. K. Agrawal

Brookhaven National Laboratory

Prepared for

U.S. Nuclear Regulatory

Commission

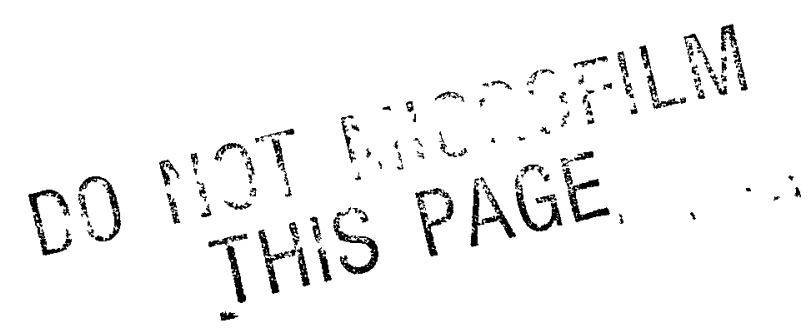

Report Issue Date: March 1983 


\section{DISCLAIMER}

This report was prepared as an account of work sponsored by an agency of the United States Government. Neither the United States Government nor any agency Thereof, nor any of their employees, makes any warranty, express or implied, or assumes any legal liability or responsibility for the accuracy, completeness, or usefulness of any information, apparatus, product, or process disclosed, or represents that its use would not infringe privately owned rights. Reference herein to any specific commercial product, process, or service by trade name, trademark, manufacturer, or otherwise does not necessarily constitute or imply its endorsement, recommendation, or favoring by the United States Government or any agency thereof. The views and opinions of authors expressed herein do not necessarily state or reflect those of the United States Government or any agency thereof. 


\section{DISCLAIMER}

Portions of this document may be illegible in electronic image products. Images are produced from the best available original document. 
This report was prepared as an account of work sponsored by an agency of the United States Government. Neither the United States Government nor any agency thereof, or any of their employees, makes any warranty, expressed or implied, or assumes any legal liability of responsibility for any third party's use, or the results of such use, of any information, apparatus, product or process disclosed in this report, or represents that its use by such third party would not infringe privately owned rights.

\section{Availability of Reference Materials Cited in NRC Publications}

Most documents cited in NRC publications will be available from one of the following sources:

1. The NRC Public Document Room, 1717 H Street, N.W. Washington, DC 20555

2. The NRC/GPO Sales Program, U.S. Nuclear Regulatory Commission, Washington, DC 20555

3. The National Technical Information Service, Springfield, VA 22161

Although the listing that follows represents the majority of documents cited in NRC publications, it is not intended to be exhaustive.

Referenced documents available for inspection and copying for a fee from the NRC Public Document Room include NRC correspondence and iriternal NRC memoranda; NRC Office of Inspection and Enforcement bulletins, circulars, information notices, inspection and investigation notices; Licensee Event Reports; vendor reports and correspondence; Commission papers; and applicant and licensee documents and correspondence.

The following documents in the NUREG series are available for purchase from the NRC/GPO Sales Program: formal NRC staff and contractor reports, NRC-sponsored conference proceedings, and NRC bookiets and brochures. Also available are Regulatory Guides, NRC regulations in the Code of Federal Regulations, and Nuclear Regulatory Commission /ssuances.

Documents available from the National Technical Information Service include NUREG series reports and technical reports prepared by other federal agencies and reports prepared by the Atomic Energy Commission, forerunner agency to the Nuclear Regulatory Commission.

Documents available from public and special technical libraries include all open literature items, such as books, journal and periodical articles, and transactions. Federal Register notices, federal and state legislation, and congressional reports can usually be obtained from these libraries.

Documents such as theses, disser.ations, foreign reports and translations, and non-NRC conference proceedings are available for purchase trom the organization sponsoring the publication cited.

Single copies of NRC draft reports are available free upon written request to the Division of Technical Information and Document Control, U.S. Nuclear Regulatory Commission, Washington, DC 20555.

Copies of industry codes and standards used in a substantive manner in the NRC regulatory process are maintained at the NRC Library, 7920 Norfolk Avenue, Bethesda, Maryland, and are available there for reference use by the public. Codes and standards are usually copyrighted and may be purchased from the orıginating organization or, if they are American National Standards, from the American National Standards Institute, 1430 Broadway, New York, NY 10018. 


\title{
Comparison of CRBR Design- Basis Events with Those of Foreign LMFBR Plants
}

\author{
NUREG/CR--3240
}

DE83 012312

Manuscript Completed: January 1983

Date Published: April 1983

Prepared by

A. K. Agrawal

Brookhaven National Laboratory

Department of Nuclear Energy

Upton, NY 11973

\section{Prepared for}

Clinch River Breeder Reactor Project Office

Office of Nuclear Reactor Regulation

U.S. Nuclear Regulatory Commission

Washington, D.C. 20555

NRC FIN A3364

\section{DISCLAIMER}

his account of work sponsored by an agency of the United States Neither the United States Government nor any agency thereof, nor any of their y warranty, express or implied, or assumes any legal liability or responsi-

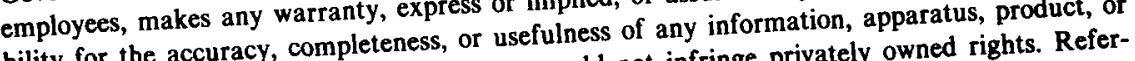
bility for the accuracy, completers ould not infringe privately owned rights. Referprocess disclosed, or represents that its use wet, process, or service by trade name, trademark, ence herein to any specific commercial product, procestitute or imply its endorsement, recommanufacturer, or otherwise does not necessarily constitute or any agency thereof. The views mendation, or favoring by the United States Government and opinions of authors expressed herein do not

United States Government or any agency thereof. 


\section{NOTICE}

This report was prepared as an account of work sponsored by an agency of the United States Government. Neither the United States Government nor any agency thereof, or any of their employees, makes any warranty, expressed or implied, or assumes any legal liability of responsibility for any third party's use, or the results of such use, of any information, apparatus, product or process disclosed in this report, or represents that its use by such third party would not infringe privately owned rights.

\section{Availability of Reference Materials Cited in NRC Publications}

Most documents cited in NRC publications will be available from one of the following sources:

1. The NRC Public Document Room, 1717 H Street. N.W. Washington, DC 20555

2. The NRC/GPO Sales Program, U.S. Nuclear Regulatory Commission. Washington, DC 20555

3. The National Technical Information Service, Springfield, VA 22161

Although the listing that follows represents the majority of documents cited in NAC publications, it is not intended to be exhaustive.

Referenced documents available for inspection and copying for a fee from the NRC Public Document Room include NRC correspondence and irternal NRC memoranda; NRC Office of Inspection and Enforcement bulletins, circulars, information notices, inspection and investigation notices: Licensee Event Reports; vendor reports and correspondence; Commiscion papers; and applicant and licensee documents and correspondence.

The following documents in the NUREG series are available for purchase from the NRC/GPO Sales Program: formal NRC staff and contractor reports, NRC-sponsored conference proceedings, and NRC booklets and brochures. Also available are Regulatory Guides, NRC regulations in the Code of Federal Regulations, and Nuclear Regulacory Commission Issuances.

Documents available from the National Technical Information Service include NUREG series reports and technical reports prepared by other federal agencies and reports prepared by the Atomic Energy Commission, forerunner agency to the Nuclear Regulatory Commission.

Documents available from public and tpecial technical libraries include all open literature items. such as books, journal and periodical articles, and transactions. Federal Register notices, federal and - state legislation, and congressional reports can usually be obtained from these libraries.

Documents such as theses, dissertations, foreign reports and translations, and non-NRC conference proceedings are available for purchase from the organization sponsoring the publication cited.

Single copies of NRC draft reports are available free upon written request to the Division of Technical Information and Document Control, U.S. Nuclear Regulatory Commission. Washington, DC 20555.

Copies of industry codes and standards used in a substantive manner in the NRC regulatory process are maintained at the NRC Library. 7920 Norfolk Avenue, Bethesda, Maryland, and are available there for reference use by the public. Codes and standards are usually copyrighted and may be purchased from the originating organization or, if they are American National Standards, from the American National Standards Institute. 1430 Broadway. New York. NY 10018.

GPO Printed copy price: $1 / 5,00$ 


\section{ABSTRACT}

As a part of the Construction Permit (CP) review of the $C l$ inch River Breeder Reactor Plant (CRBR), the Brookhaven National Laboratory was asked to compare the Design Basis Accidents that are considered in CRBR Preliminary Safety Analysis Report with those of the foreign contemporary plants (PHENIX, SUPERPHENIX, SNR-300, PFR, and MONJU). A brief introductory review of any special or unusual characteristics of these plants is given. This is followed by discussions of the design basis accidents and their acceptance criteria. In spite of some discrepancies due either to semantics or to licensing decisions, there appears to be a considerable degree of unanimity in the selection (definition) of DBAs in all of these plants. 


$$
\therefore
$$




\section{TABLE OF CONTENTS}

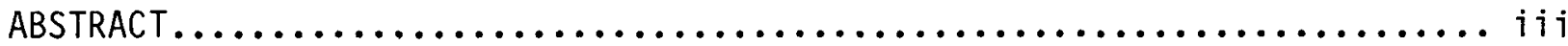

LIST OF FIGURES $\ldots \ldots \ldots \ldots \ldots \ldots \ldots \ldots \ldots \ldots \ldots \ldots \ldots \ldots \ldots \ldots \ldots \ldots \ldots \ldots \ldots \ldots \ldots$

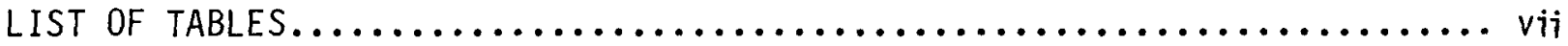

1. INTRODUCTION ..................................... 1

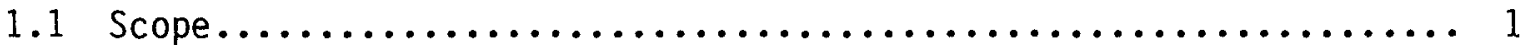

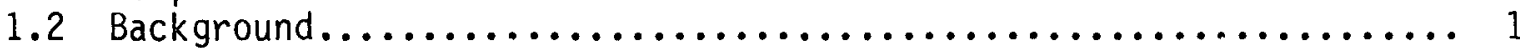

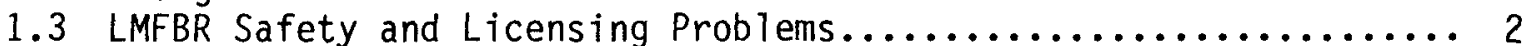

1.4 The Applicant's Position and Justification................. 4

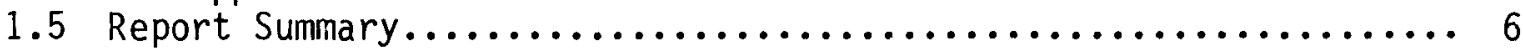

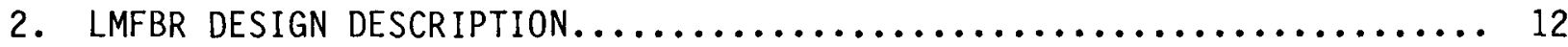

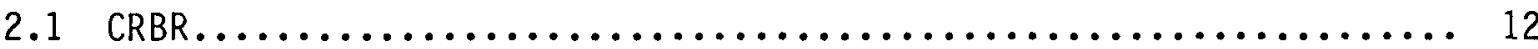

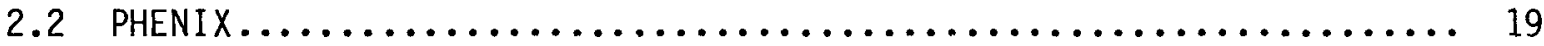

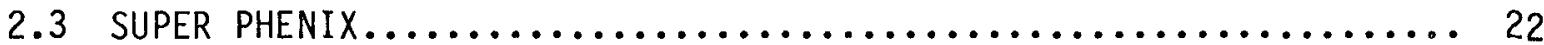

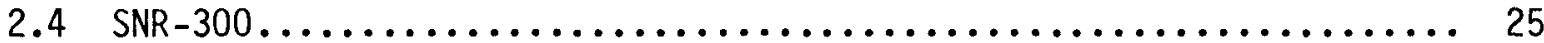

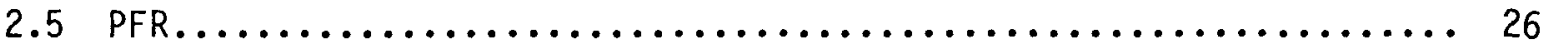

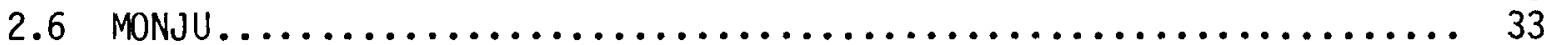

3. DISCUSSIONS.................................... 34

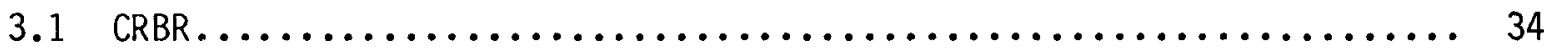

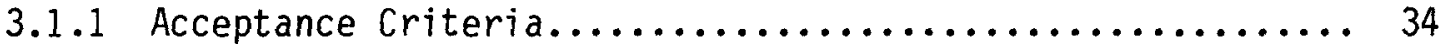

3.1.2 Design Basis Accident and Analyses................. 34

3.2 SUPER PHENIX.................................. 41

3.2.1 Design Basis Accidents and Requirements............. 41

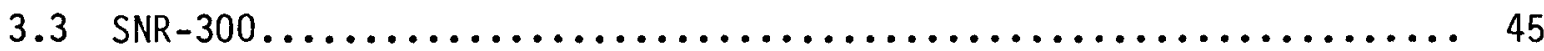

3.3.1 Design Basis Accidents and Requirements.............. 45

3.3 .2 Transient Analysis........................... 48

$3.4 \mathrm{MONJU} \ldots \ldots \ldots \ldots \ldots \ldots \ldots \ldots \ldots \ldots \ldots \ldots \ldots \ldots \ldots \ldots \ldots \ldots \ldots \ldots \ldots \ldots \ldots$

3.4.1 Safety Design Criteria......................... 50

3.4 .2 Design Basis Accidents......................... 59

3.5 General Comments............................... 67

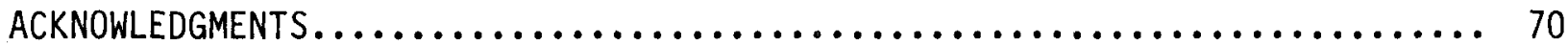

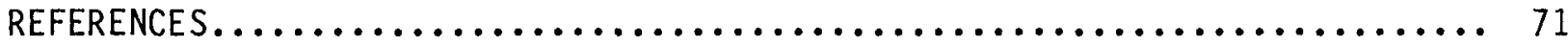




\section{LIST OF FIGURES}

Figure

Title

$\underline{\text { Page }}$

1 A simplified illustration of the DBA and beyond DBA events...... 5

$2 \quad$ CRBR plant layout................................ 13

$3 \quad$ CRBR heterogeneous core design........................ 18

4 PHENIX plant layout............................... 20

5 SUPER PHENIX plant layout........................... 24

$6 \quad$ SNR-300 reactor vesset schematic...................... 27

$7 \quad$ SNR-300 plant layout...................................... 28

$8 \quad$ SNR-300 shutdown system design....................... 30

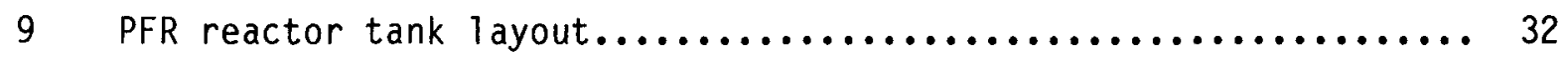




\section{LIST OF TABLES}

Table

Title

Page

I. $\quad$ LMFBR projects.................................. 3

II. Representative types of events to be analyzed in Chapter 15.0 of the SAR per SFAC................................. 7

II I. Additional events considered by the applicant.............. 11

IV. Key design data for contemporary LMFBR plants............... 14

V. Comparison between the first and second shutdown systems of

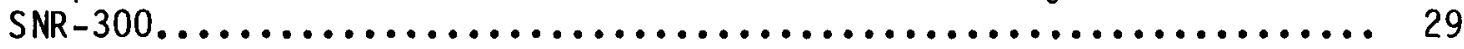

VI. Event classification and damage severity limits for CRBR....... 35

VII. Acceptance criteria for preliminary safety evaluation for CRBR.... 36

VIII. Primary and secondary shutdown system damage severity limits for CRBR....................................... 37

IX. Classification of accidents used in MONJU.................. 51

X. List of abnormal events considered and the results of analysis for

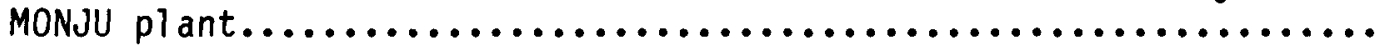

XI. List of accident events considered and the results of analysis for MONJU plant.......................................... 64

XII. A comparison of shutdown heat removal systems.............. 69 


\section{INTRODUCTION}

\subsection{Scope}

As part of the Construction Permit (CP) review of the $\mathrm{Cl}$ inch River Breeder Reactor Plant (CRBR), the Brookhaven National Laboratory was asked to compare the Design Basis Accidents (DBA) that are considered by the applicant in their Prel iminary Safety Analysis Report (PSAR) with those of the foreign contemporary plants such as PHENIX and SUPER PHENIX in France, SNR-300 in the Federal Republic of Germany, PFR in Great Britain, and MONJU in Japan. In a companion effort, the Idaho National Engineering Laboratory was asked to compare the CRBR DBA events with those considered by other domestic LMFBR facilities (including EBR-I, EBR-II, FERMI, SEFOR, FFTF, and LDP). This report is the result of findings on the foreign plants. Hanson [1] has compiled a report on the domestic DBA comparison study.

The current study has been somewhat affected by the lack of public availability of the PSARs or their equivalents for foreign plants. In general, public documents on foreign plants tend to be either design oriented or they discuss beyond design basis accidents or the hypothetical core disruptive accidents. A complete comparison of DBAs, therefore, was a difficult task. The compilation within this report is based on the published reports as well as data obtained at a personal level.

This report is organized as follows: The first part includes a brief background of LMFBR design, operating experiences, and the safety issues, followed by the applicant's position and summary of the report. The second part is an attempt to include key design features of the foreign plants. This is done to put in perspective other design options and their significance. Discussions of the types of accident events considered by different countries are noted in the third part. Finally, a list of documents/papers reviewed or potentially useful papers are noted under bibliography.

\subsection{Background}

The first nuclear reactor ever to generate electrical energy was a liquidmetal fast breeder reactor-the Experimental Breeder Reactor-I (EBR-I) when it lit a bulb on 20th December 1951. Since then, more than thirty-one years of research and development programs both in the United States and overseas (most notably France, Federal Republ ic of Germany, Great Britain, India, Italy, Japan, and the U.S.S.R.) have resulted in a mature LMFBR technology to the point that large experimental plants such as EBR-II and FFTF in the U.S.A., Rapsodie in France, KNK-2 in F.R.G., DFR in Great Britain, FBTR in India, JoYO in Japan, and BR-10, BOR-60 in the U.S.S.R., are currently operational. Such demonstration-size plants as the PHENIX in France, PFR in Great Britain, and $\mathrm{BN}-350$ in the U.S.S.R. have also been in operation for a minimum of eight years. Commercial-size plants have al so advanced significantly. For example, $\mathrm{BN}-600$ in the U.S.S.R. has been in operation since February 1980, and France's SUPER PHENIX is expected to go critical in 1983. In this comparison, the Clinch River Breeder Reactor Plant (CRBRP) is only a demonstration-size American plant. More than 130 reactor years of operating experience with 
either experimental, demonstration or commercial-size LMFBR plants have now been attained (see Table I).

Experience gained from the above-mentioned LMFBR projects have resulted in basically two different designs - loop-type and pool-type plants. In both designs, the primary radioactive sodium transfers heat to the water/steam circuit via an intermediate sodium heat transfer system. The key difference is that in the loop designs, the reactor vessel contains fuel, blanket, control, and shielding assemblies, and the nuclear-generated heat is piped through a piping network, pump, and the intermediate heat exchanger all placed outside the reactor vessel. In pool designs, the entire radioactive primary cooling system is integrated in a large tank filled with sodium. Penetrations to this tank are provided for intermediate sodium pipes.

There are favorable aspects of both 1 oop and pool designs. The loop systems have smaller radioactive sodium inventories and employ more compact reactor vessels than those of the pool systems. The loop systems al so provide greater flexibility in maintenance of key components such as valves, pumps, and the intermediate heat exchangers. They also offer, generally speaking, simpler vessel head designs, but several penetrations for the inlet and outlet of sodium must be provided. The loop systems are more susceptible to severe pipe ruptures than the pool systems but the secondary vessels and the guard pipe can provide acceptable mitigative protection.

The pool designs, on the other hand, involve much larger primary sodium inventory which provides considerably larger thermal inertia than the loop systems do. No coolant nozzle penetrations are involved but the reactor vessel head becomes rather complicated as all connections with the intermediate heat transfer circuit must go through them. The severity of consequences due to primary pipe rupture is almost insignificant. Amongst the disadvantages of the pool designs, the increased size, severe thermal transients, and seismic factors are the key ones. Al so a much larger inventory of radioactive sodium has to be handled, thereby a potential exists for more energetic sodium fires than in the loop designs. Either of the two designs can be built to meet the requirements imposed on them. The choice between the two concepts, of course, has to be made on the basis of detailed consideration of such factors as past design and operating experiences as well as 1 icensing needs.

\subsection{LMFBR Safety and Licensing Issues}

LMFBR safety issues tend to be rather dissimilar to those of LWRs in several ways. To begin with, LMFBRs are cooled by liquid sodium which has excellent heat removal characteristics. In a properly designed plant, the natural convection that is established can be sufficient to remove the shutdown heat passively. Secondly, the system is at essentially "zero" pressure and operates at the peak sodium temperature of several hundred degrees (Fahrenheit) below the coolant saturation temperature at the atmospheric pressure. The coolant flashing is therefore not possible. The consequences of a loss of coolant accident ( $L O C A$ ) via massive pipe rupture can be designed to be rather benign. The pool-type designs provide better protection but in the loop-type designs (e.g., CRBR), a double-wall (i.e., a guard pipe) concept is used to mitigate the consequences. Alternatively, the most critical region of the pipe (i.e., 
Table I. LMFBR Projects

\begin{tabular}{|c|c|c|c|c|}
\hline Reactor & $\begin{array}{l}\text { Power, MW } \\
\text { (thermal/ } \\
\text { electrical) }\end{array}$ & $\begin{array}{l}\text { Basic } \\
\text { Design }\end{array}$ & $\begin{array}{l}\text { Type of } \\
\text { Facility }\end{array}$ & $\begin{array}{l}\text { Years of Operation } \\
\text { till 1982 }\end{array}$ \\
\hline $\begin{array}{l}\text { France } \\
\text { Rapsodie } \\
\text { PHENIX } \\
\text { SUPER PHENIX }\end{array}$ & $\begin{array}{c}40 /- \\
563 / 250 \\
3000 / 1200\end{array}$ & $\begin{array}{l}\text { Loop } \\
\text { Pool } \\
\text { Pool }\end{array}$ & $\begin{array}{l}\text { Experimental } \\
\text { Demonstration } \\
\text { Commercial }\end{array}$ & $\begin{array}{c}9 \\
8 \\
\text { Criticality } 1983\end{array}$ \\
\hline $\begin{array}{l}\text { Germany, F.R. } \\
\text { KNK-2 } \\
\text { SNR-300 }\end{array}$ & $\begin{array}{c}58 / 20 \\
762 / 327\end{array}$ & $\begin{array}{l}\text { Loop } \\
\text { Loop }\end{array}$ & $\begin{array}{l}\text { Experimental } \\
\text { Demonstration }\end{array}$ & $\frac{5}{\text { Criticality' } 84-{ }^{\prime} 85}$ \\
\hline$\frac{\text { Great Britain }}{\text { DFR }}$ & $600 / 250$ & Pool & Demonstration & $\begin{array}{l}\text { Decommissioned } \\
\text { after } 18 \text { yrs of } \\
\text { operation } \\
\qquad 9\end{array}$ \\
\hline$\frac{\text { India }}{\text { FBTR }}$ & $42.5 / 15$ & Loop & Experimental & Criticality 1983 \\
\hline $\begin{array}{l}\frac{\text { Japan }}{\text { JOYO }} \\
\text { MONJU }\end{array}$ & $\begin{array}{l}100 /- \\
714 / 300\end{array}$ & $\begin{array}{l}\text { Loop } \\
\text { Loop }\end{array}$ & $\begin{array}{l}\text { Experimental } \\
\text { Demonstration }\end{array}$ & $\begin{array}{c}5 \\
\text { Criticality } 1987\end{array}$ \\
\hline $\begin{array}{l}\text { U.S.S.R. } \\
\text { BR-5 } \\
\text { BR-10 } \\
\text { BOR-60 } \\
\text { BN-350 } \\
\text { BN-600 } \\
\text { BN-800 }\end{array}$ & $\begin{array}{c}5 /- \\
10 /- \\
60 / 12 \\
1000 / 350 \\
1470 / 600 \\
\pi / 800\end{array}$ & $\begin{array}{l}\text { Loop } \\
\text { Loop } \\
\text { Loop } \\
\text { Loop } \\
\text { Pool } \\
\text { Pool }\end{array}$ & $\begin{array}{l}\text { Experimental } \\
\text { Experimental } \\
\text { Experimental } \\
\text { Demonstration } \\
\text { Commercial } \\
\text { Commercial }\end{array}$ & $\begin{array}{c}15 \\
\text { (upgraded to BR-10) } \\
9 \\
13 \\
10 \\
2 \\
\text { Criticality } 1985\end{array}$ \\
\hline$\frac{\text { U.S.A. }}{\text { EBR-I }}$ & $1 / 0.2$ & Loop & Experimental & $\begin{array}{l}\text { Decommissioned } \\
\text { after } 7 \text { years of } \\
\text { operation }\end{array}$ \\
\hline $\begin{array}{l}\text { EBR-II } \\
\text { FERMI }\end{array}$ & $\begin{array}{r}62.5 / 20 \\
200 / 66\end{array}$ & $\begin{array}{l}\text { Pool } \\
\text { Loop }\end{array}$ & $\begin{array}{l}\text { Experimental } \\
\text { Experimental }\end{array}$ & $\begin{array}{l}19 \\
\text { Decommissioned } \\
\text { after } 9 \text { years of } \\
\text { operation }\end{array}$ \\
\hline SEFOR & $20 /-$ & Loop & Experimental & $\begin{array}{l}\text { Decommissioned } \\
\text { after } 3 \text { years of } \\
\text { operation }\end{array}$ \\
\hline $\begin{array}{l}\text { FFTF } \\
\text { CRBR }\end{array}$ & $\begin{array}{l}400 /- \\
975 / 350\end{array}$ & $\begin{array}{l}\text { Loop } \\
\text { Loop }\end{array}$ & $\begin{array}{l}\text { Experimental } \\
\text { Demonstration }\end{array}$ & 2 \\
\hline
\end{tabular}


the downcomer) can be located inside the reactor vessel (such as in the SNR300 ) and thus protection is significantly improved.

LMFBR transient events have been categorized in a number of ways: The applicant makes use of three levels of design; the American Society of Mechanical Engineers (ASME) classifies plant conditions into four categories according to their anticipated frequency of occurrence and the potential radiological consequences to the public; and the AEC's definition of Class 1-9 events (these were proposed by AEC in 1971 but have now been withdrawn by NRC). The intent of all of these classifications is to ascertain that the safety analysis of a plant is carried out systematically. The ultimate goal of these categorizations is to develop a comprehensive set of DBA events. In fact, the two major kinds of decisions to be made in LMFBR licensing are the following:

(1) The definition of the set of DBA events to be used in the project design, safety analysis, and fulfillment of the radiological consequence limitations.

(2) Definition of the design requirements for beyond design basis events that must also be considered in developing the engineered safety systems.

A simplified illustration of the connection between the DBA events and beyond DBA is shown in Fig. 1. The beyond DBA events are generally accidents in which an anticipated transient occurs and is not followed by an automatic scram when required. These are also some times called Anticipated Transients Without Scram (ATWS). Generally speaking, these accidents involve at least some degree of fuel melting or core disruption (also known as Hypothetical Core Di sruptive Accidents, HCDA). Special accommodation devices may then be required to contain the consequences of these beyond design basis events.

\subsection{The Applicant's Position and Justification}

The applicant's approach to the CRBR safety analysis is developed upon three levels of design. The first level focuses on the reliability of operation and prevention of accidents through such intrinsic features as design, construction, and operation of the plant. The second level focuses on protection against "Anticipated" and "Unlikely" faults which might be expected to occur at least once during the plant's lifetime. The third focuses on low probability "Extremely Unlikely" events which are included in the Design Basis Accident events. These events are not expected to occur during the plant's lifetime. In addition to the three levels of design, the applicant has also considered what they term as the beyond design basis accidents and provided the engineering safety features to accommodate them. These beyond design basis events are primarily the hypothetical core disruptive accidents involving various degrees of core melt.

The applicant has relied on a number of sources in selecting the DBA events for CRBR. These sources include (1) Standard Format and Content of Safety Analysis Reports for Nuclear Power Plants-LMFBR Edition [2], (2) the similar document for the water reactors [3], and (3) operating experience gained from other LMFBR facilities such as EBR-II and FFTF and to a small extent from 


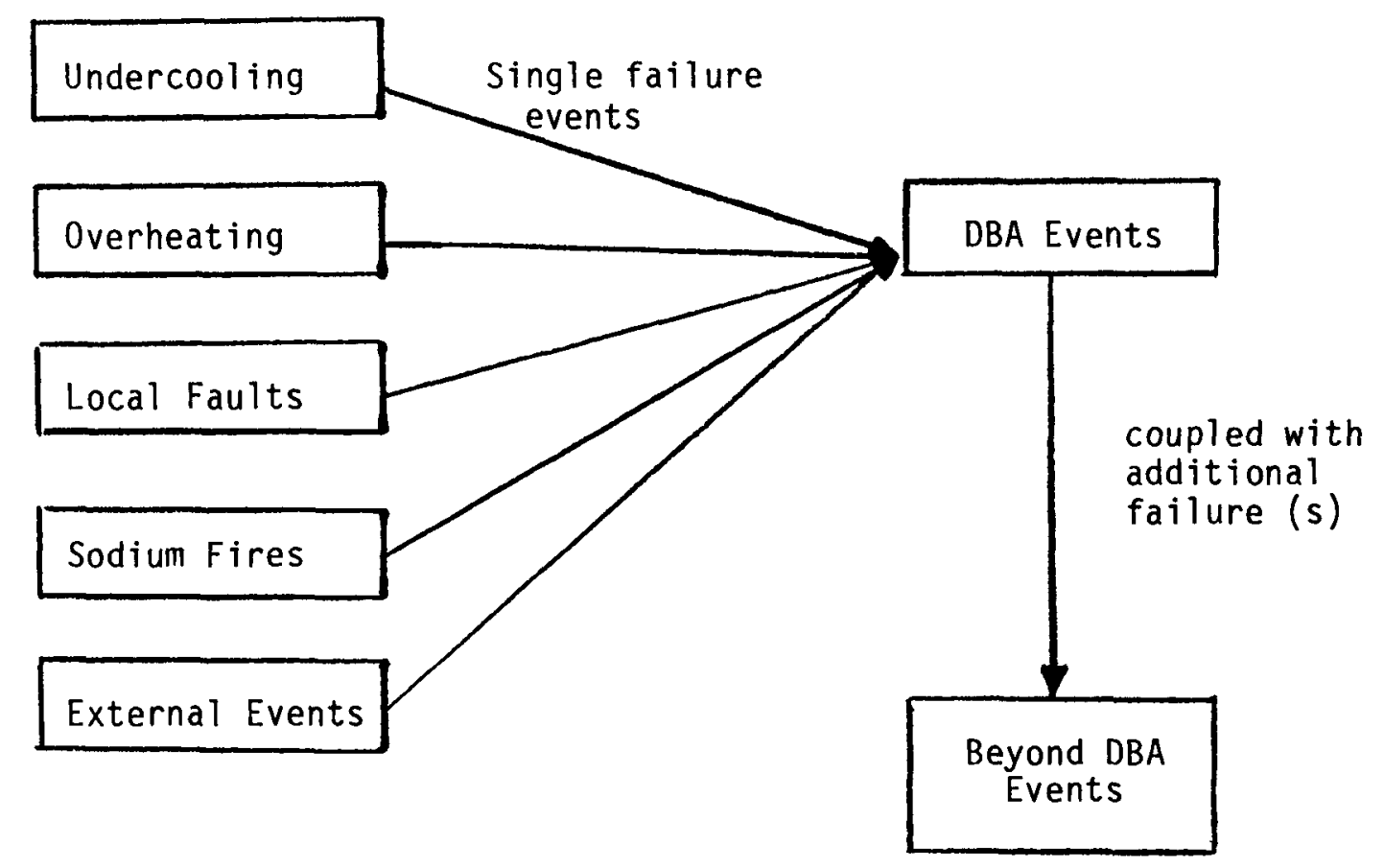

Figure 1 A simplified illustration of the DBA and beyond DBA events. 
foreign LMFBRs. The SFAC for LMFBRs provided a list of 67 events that must be considered in the DBA evaluation. These events, shown in Table II, are representative but not necessarily conclusive. The applicant has al so identified an additional five events (listed in Table III). All of these seventy-two events were categorized as follows:
(a) Reactivity insertion events
(b) Undercooling events
(c) (In-core) local failure events
(d) Fuel handling and storage events
(e) Sodium spills and fires
(f) Other events

These have been analyzed in the Chapter 15.0 of the PSAR. The adequacy of the analysis of these events is not considered in this report (this is being addressed separately by Brookhaven National Laboratory and the Los AI amos

National Laboratory).

A remaining potential issue is whether all significant accidents have been considered by the applicant. In this connection, it is important to note that the applicant has voluntarily agreed to identify and quantify all accident initiators via the use of the fault trees and event trees as a part of his PRA work. In addition these accident events have also been compared (see Ref. [1]) with those used in other domestic LMFBR facilities.

\subsection{Report Summary}

PHENIX, SUPER PHENIX, SNR-300, PFR, and MONJU plants are briefly described in Chapter 2. Any unusual or special characteristics of these plants, as evidenced through the available reports, are also noted here.

Chapter 3 discusses the design basis accidents, acceptance criteria, and the analyses of DBAs for CRBR, SUPER PHENIX, SNR-300, and MONJU plants. Although there is a considerable degree of unanimity in the selection of DBAs, some difficulties prevail due either to semantics or to licensing decisions. All of these plants have redundant and diverse shutdown systems. The shutdown heat removal systems do differ appreciably in terms of their diversity and reliability. 
Table II. Representative types of events to be analyzed in Chapter 15.0 of the SAR per SFAC

\begin{tabular}{|c|c|}
\hline Number & Event Description \\
\hline 1 & $\begin{array}{l}\text { Uncontrolled control rod assembly withdrawal from a subcritical } \\
\text { condition assuming the most unfavorable reactivity conditions of } \\
\text { the core and reactor coolant system. }\end{array}$ \\
\hline 2 & $\begin{array}{l}\text { Uncontrolled control rod assembly withdrawal at power assuming } \\
\text { the most unfavorable reactivity conditions of the core and reactor } \\
\text { coolant system which yield the most severe results (hot at zero } \\
\text { power, full power, etc). }\end{array}$ \\
\hline 3 & Control rod misoperation or sequence of misoperations. \\
\hline 4 & $\begin{array}{l}\text { Partial and total loss of reactor coolant flow including trip of } \\
\text { pumps and pump seizures. }\end{array}$ \\
\hline 5 & $\begin{array}{l}\text { Start-up of an inactive reactor coolant loop or recirculating loop } \\
\text { at incorrect temperature. }\end{array}$ \\
\hline 6 & Loss of normal and/or emergency feedwater flow. \\
\hline 7 & $\begin{array}{l}\text { Loss of all ac power to the station auxiliaries and loss of } \\
\text { emergency diesel generators (station blackout). }\end{array}$ \\
\hline 8 & Loss of intermediate coolant flow. \\
\hline 9 & $\begin{array}{l}\text { Heat removal greater than heat generation due to (1) feedwater } \\
\text { system malfunctions, ( } 2 \text { ) a pressure regulator failure, or } \\
\text { inadvertent opening of a relief valve or safety valve, and (3) a } \\
\text { regulating instrument failure. }\end{array}$ \\
\hline 10 & Maloperation of reactor plant controllers. \\
\hline 11 & $\begin{array}{l}\text { Internal and external events such as major and minor fires, flood, } \\
\text { storms, or earthquakes. }\end{array}$ \\
\hline 12 & $\begin{array}{l}\text { Loss of coolant accidents resulting from the spectrum of postulat- } \\
\text { ed piping breaks within the reactor coolant system. }\end{array}$ \\
\hline 13 & $\begin{array}{l}\text { Spectrum of postulated intermediate coolant system piping breaks } \\
\text { inside and outside containment. }\end{array}$ \\
\hline 14 & $\begin{array}{l}\text { Inadvertent loading and operation of a fuel assembly into an } \\
\text { improper position. }\end{array}$ \\
\hline 15 & Waste gas decay tank leakage or rupture. \\
\hline
\end{tabular}


Table II. Representative types of events to be analyzed in Chapter 15.0 of the SAR per SFAC (Cont.)

\begin{tabular}{|c|c|}
\hline Number & Event Description \\
\hline 16 & Failure of cover gas purification system. \\
\hline 17 & The spectrum of rod ejection accidents. \\
\hline 18 & Fuel-handling accident. \\
\hline 19 & Small spills or leaks of radioactive material outside containment. \\
\hline 20 & $\begin{array}{l}\text { Fuel cladding failure combined with intermediate heat exchanger and } \\
\text { steam generator leaks. }\end{array}$ \\
\hline 21 & Control room uninhabitability. \\
\hline 22 & Loss of heat sink. \\
\hline 23 & $\begin{array}{l}\text { Turbine trip with coincident failure of turbine bypass valves to } \\
\text { open. }\end{array}$ \\
\hline 24 & Loss of one (redundant) dc system. \\
\hline 25 & Turbine trip with failure of generator breaker to open. \\
\hline 26 & Loss of instrument air system. \\
\hline 27 & Local blockages of a few subchannels within a fuel subassembly. \\
\hline 28 & Leak in control rod drive housing. \\
\hline 29 & Inadvertent release of oil in pump seal into sodium. \\
\hline 30 & Failure of a few steam generator tubes. \\
\hline 31 & Leaks in intermediate heat exchanger. \\
\hline 32 & Abnormally high or low cover gas pressure. \\
\hline 33 & Core flow maldistribution due to fuel loading error. \\
\hline 34 & Gas bubbles passing through core. \\
\hline 35 & Failure of steam dump system. \\
\hline 36 & $\begin{array}{l}\text { Inadvertent closure of either reactor coolant valves or inter- } \\
\text { mediate coolant valves. }\end{array}$ \\
\hline 37 & Spurious reactor trip. \\
\hline
\end{tabular}


Table II. Representative types of events to be analyzed in Chapter 15.0 of the SAR per SFAC (Cont.)

\begin{tabular}{|c|c|}
\hline Number & Event Description \\
\hline 38 & Inadvertent drop (delatching) of a single control rod. \\
\hline 39 & Failure of reactor vessel cover seal. \\
\hline 40 & Plugging of reactor overflow line. \\
\hline 41 & Failure of core clamping mechanism. \\
\hline 42 & Accidental opening of valves to a drained isolated loop. \\
\hline 43 & Large leak (rupture) in steam or feedwater piping. \\
\hline 44 & Enrichment error in fuel assembly. \\
\hline 45 & Misloaded fuel assembly. \\
\hline 46 & Dropped fuel assembly. \\
\hline 47 & Unknown stuck control rod. \\
\hline 48 & Loss of normal shutdown cooling system. \\
\hline 49 & Simultaneous leak of reactor overfl ow tank. \\
\hline 50 & $\begin{array}{l}\text { Inadvertent closure of floor valve on canister during fuel } \\
\text { handling. }\end{array}$ \\
\hline 51 & Failure of any single active component in fuel handling system. \\
\hline 52 & Loss of site power during fuel handling. \\
\hline 53 & Fuel-handling machine jams. \\
\hline 54 & Leak in fuel storage vessel. \\
\hline 55 & Failure of single active component in fuel storage cooling system. \\
\hline 56 & Failure to seat fuel assembly properly. \\
\hline 57 & $\begin{array}{l}\text { Inadvertent opening of floor valve with shield plug removed and } \\
\text { fuel-handling machine not in place. }\end{array}$ \\
\hline 58 & Leak in fuel canister. \\
\hline
\end{tabular}


Table II. Representative types of events to be analyzed in Chapter 15.0 of the SAR per SFAC (Cont.)

\begin{tabular}{|c|l|}
\hline Number & \multicolumn{1}{|c|}{ Event Description } \\
\hline 59 & Inadvertent opening of fuel-handling machine valve during transfer \\
60 & Attempt to insert a fuel assembly into occupied position. \\
61 & Collision of fuel-handling machine with control rods. \\
62 & Dropping shipping cask from maximum possible crane height. \\
63 & Collision between fuel-handling machine and crane. \\
64 & Loss of all power to fuel-handling machine. \\
65 & Removal of jammed fuel assembly. \\
66 & Blocked coolant flow to control rods. \\
67 & Intermediate coolant system fire. \\
\hline
\end{tabular}


Table III. Additional events considered by the applicant

\begin{tabular}{|c|l|}
\hline Number & \multicolumn{1}{|c|}{ Event Description } \\
\hline 1 & Seismic reactivity insertion due to OBE. \\
2 & Core, radial blanket, and control rod movement due to SSE. \\
3 & Sudden core radial movement. \\
4 & $\begin{array}{l}\text { Inadvertent actuation of the sodium/water reaction pressure } \\
\text { rel ief system. }\end{array}$ \\
5 & Stochastic pin failure. \\
\hline
\end{tabular}




\section{LMFBR DESIGN DESCRIPTION}

A brief description of the major salient features of the contemporary LMFBR projects including CRBR for which NRC is reviewing the CP application, PHENIX and SUPER PHENIX plants, SNR-300, PFR, and MONJU is given. A number of smaller (experimental) plants are left out. Also excluded are those plants (LDP in U.S.A., beyond SUPER PHENIX; it is a 1500-MWe plant but uses the same size reactor tank as 1200-MWe SUPER PHENIX, SNR-2, and CFR) which are in advanced stages of design, but, due to even more severe lack of detailed data, any further discussion is not possible.

\subsection{CRBR}

The $\mathrm{Clinch}$ River Breeder Reactor Plant is the first demonstration-size plant which has had the benefit, not all of it by its own choice, of more extensive design developoment and study than perhaps any other plant. It has been wide$1 y$ documented, culminating with an el aborate fourteen-plus volume Preliminary Safety Analysis Report. The reactor plant uses a loop-type design (see Fig 2) similar to that of the currently operating FFTF. It uses nearly identical fuel design. It also has a three-loop system but differs from the FFTF in that the steam generators (two evaporators and one superheater in each loop) are employed to produce steam for electric generation.

Table IV lists key design information for the CRBR plant. One of the most outstanding features of the CRBR core design is its heterogeneous arrangement of the fuel and the inner blanket assemblies (see Fig.3). In this arrangement, 156 fuel assemblies are intermixed with 82 inner blanket assemblies all of which are replaced as a batch every two years. In alternate years, six partly burned inner blanket assemblies are replaced with six fresh fuel assemblies. The heterogeneous core has two advantages: increased breeding ratio and reduced reactivity worth due to sodium void. A major distinction of the heterogeneous core is the increased complication in orificing the assemblies to avoid excessive radial temperature gradients across assemblies during their lifetime.

The reactor heat transport system is designed to take advantage of the natural convection as a passive mode of decay heat dissipation. Protection against major leakages/ruptures is provided by either a double tank system around the reactor vessel, pumps, and the IHXs, or a double pipe arrangement for pipings below the elevation of the tops of the guard vessels.

The shutdown heat removal system consists of the main primary and intermediate heat transport systems and the steam generating system as the normal (preferred) mode. In the event that the main heat sink or main feedwater supply is unavailable, a safety-related system (the Steam Generator Auxiliary Heat Removal System, SGAHRS) is provided. This system performs its functions using short- and long-term heat removal subsystems. Short term-heat removal is by venting of steam from the steam drum. The expended water is replaced by water from a protected water storage tank. Long-term heat removal is accomplished by condensing steam through a protected air-cooled condenser. In addition to the SGAHRS, a supplementary means of removing long-term decay heat is al so provided. This Direct Heat Removal Service (DHRS) system consists of circulating 


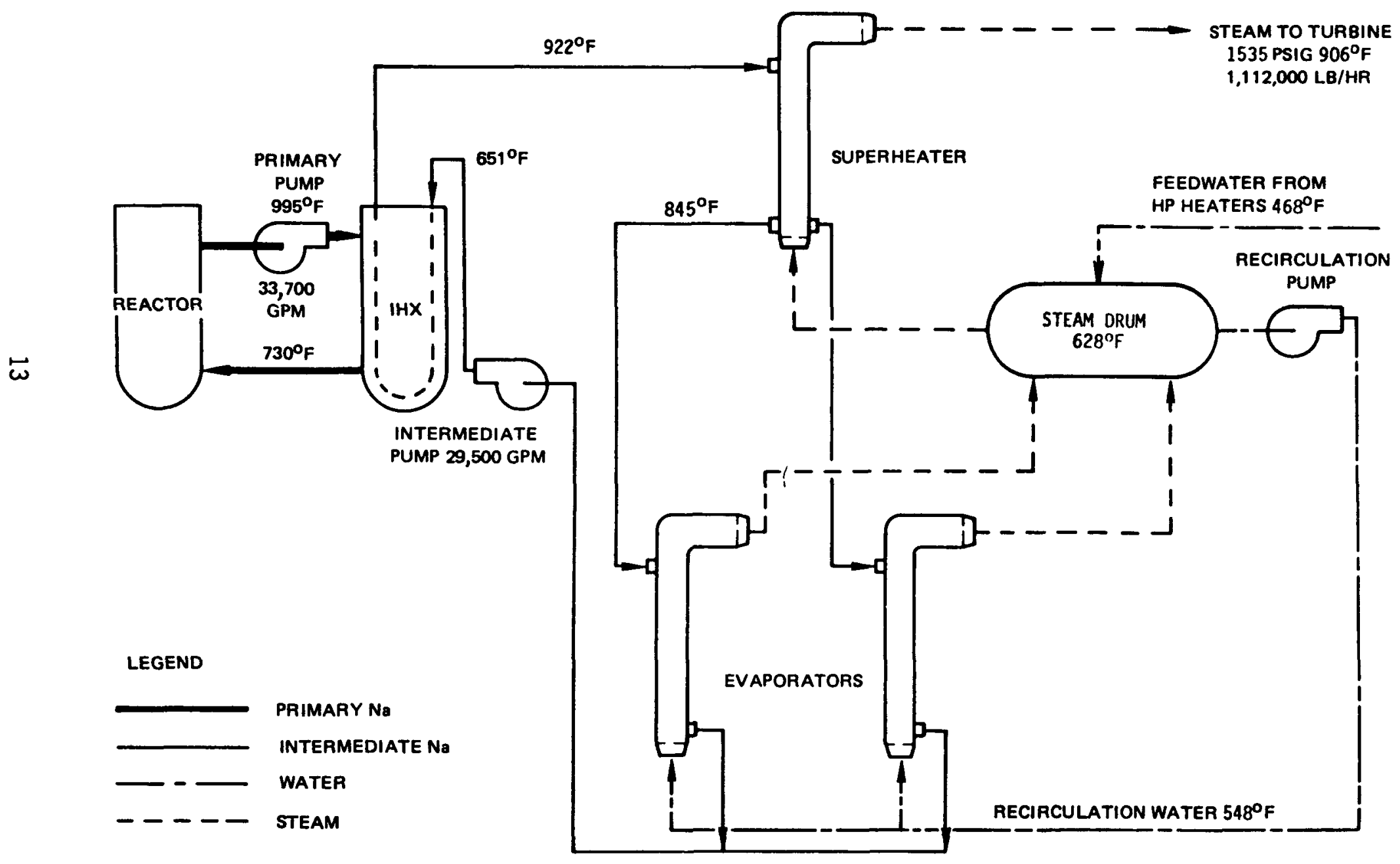

Figure 2 CRBR P lant 1 ayout. 
Table IV. Key design data for contemporary LMFBR plants

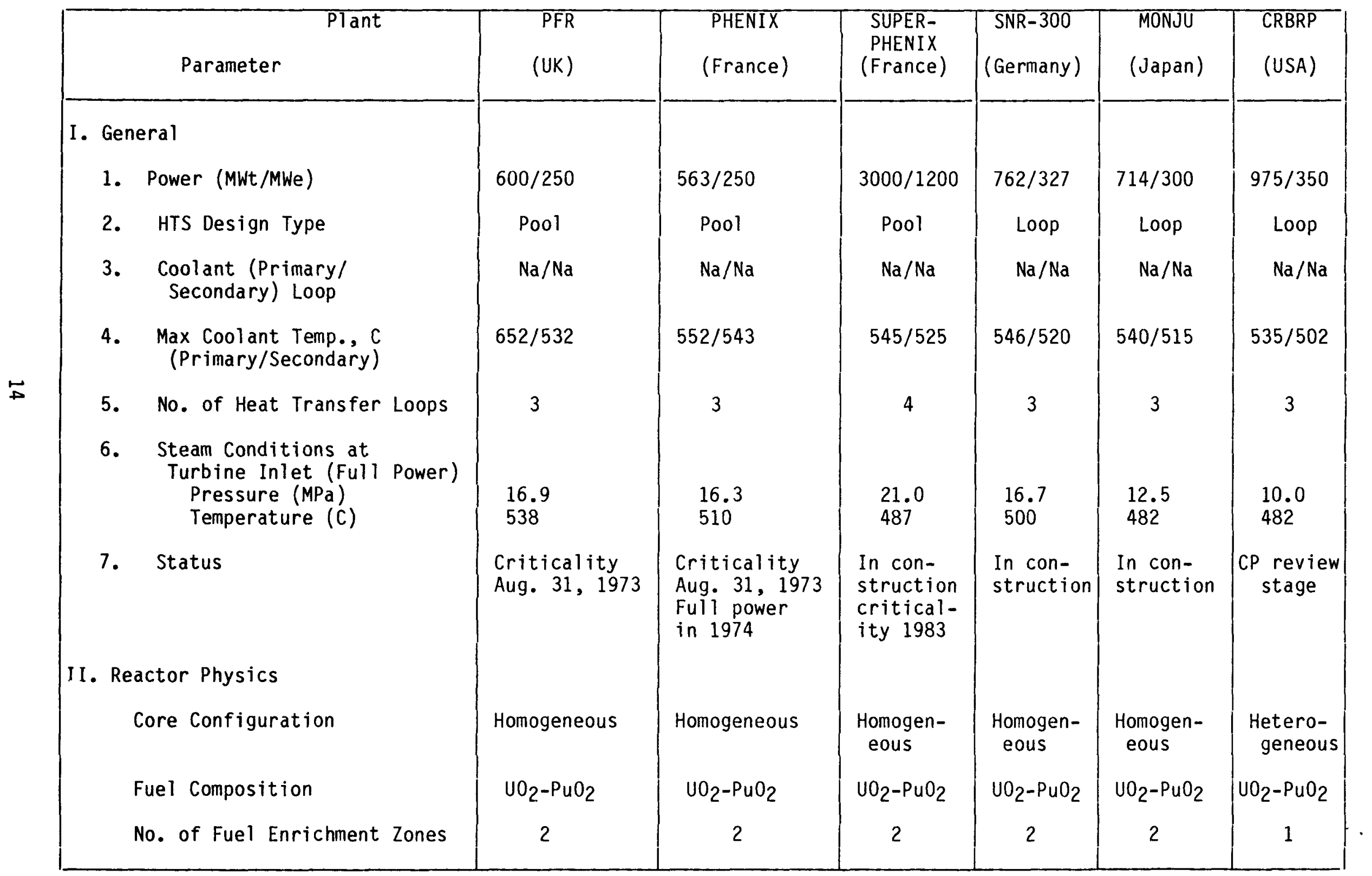


Table IV. Key design data for contemporary LMFBR plants (Cont.)

\begin{tabular}{|c|c|c|c|c|c|c|}
\hline $\begin{array}{l}\text { Plant } \\
\text { Parameter }\end{array}$ & $\begin{array}{l}\text { PFR } \\
\text { (UK) }\end{array}$ & $\begin{array}{l}\text { PHENIX } \\
\text { (France) }\end{array}$ & $\begin{array}{l}\text { SUPER- } \\
\text { PHENIX } \\
\text { (France) }\end{array}$ & $\begin{array}{l}\text { SNR-300 } \\
\text { (Germany) }\end{array}$ & $\begin{array}{l}\text { MONJU } \\
\text { (Japan) }\end{array}$ & $\begin{array}{l}\text { CRBRP } \\
\text { (USA) }\end{array}$ \\
\hline Equiv. Mean Pu-239 Enrichment (\%) & & $\sim 20 \%$ & 15.12 & & 19 & 32.8 \\
\hline Equiv. Mass of Pu-239 (kg) & & & 4800 & 1200 & & 1500 \\
\hline Core Height & 0.91 & 0.85 & 1.0 & 0.95 & 0.90 & 0.91 \\
\hline Core Diameter & & 1.39 & 3.5 & 1.78 & 1.78 & 2.02 \\
\hline Volume $\quad(\ell)$ & & 1385 & 10,000 & 2630 & 2230 & 2.500 \\
\hline Power Density & & 406 & 300 & 290 & 320 & 390 \\
\hline Refueling (months) & & & & & & \\
\hline $\begin{array}{l}\text { Peak Core Burnup ( } \% \text { heavy atom) } \\
\text { (MWd } / \mathrm{kg} \text { ) }\end{array}$ & 75 (avg) & 50 & $70(8.3 \%)$ & 90 & 80 (avg) & 110 \\
\hline $\begin{array}{r}\text { Maximum Linear Heating Rate } \\
\qquad(\mathrm{kW} / \mathrm{m})\end{array}$ & 48 & 43 & $45-48$ & 38 & & 52 \\
\hline III. Reactor Core Design & & & & & & \\
\hline No. of Fuel Assemblies & 78 & 103 & 364 & 205 & & $156+6 *$ \\
\hline No. of Pins per Fuel Assembly & 325 & 217 & 271 & 169 & 169 & 217 \\
\hline No. of Inner Blanket Assemblies & - & - & - & - & - & $76+6^{*}$ \\
\hline No. of Blanket Assemblies & 51 & 90 & 233 & 96 & & 126 \\
\hline No. of Pins per Assembly & 85 & 61 & 91 & 61 & 61 & 61 \\
\hline Mixed-Mean Core $\Delta \mathrm{T}(\mathrm{C})$ & 160 & 167 & 150 & 175 & 150 & 147 \\
\hline
\end{tabular}

*See text. 
Table IV. Key design data for contemporary LMFBR plants (Cont.)

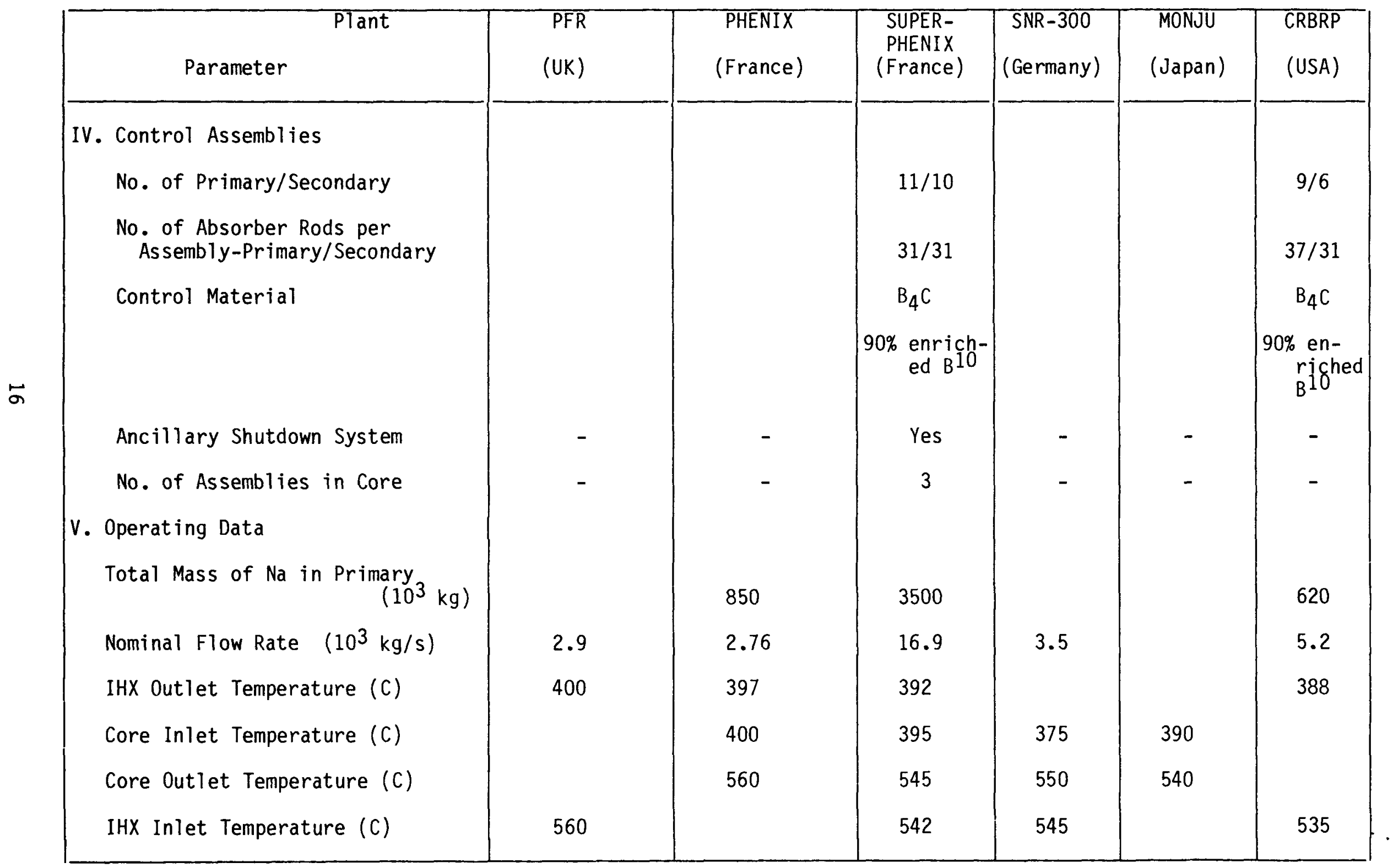


Table IV. Key design data for contemporary LMFBR plants (Cont.)

\begin{tabular}{|c|c|c|c|c|c|c|}
\hline $\begin{array}{l}\text { Plant } \\
\text { Parameter }\end{array}$ & $\begin{array}{l}\text { PFR } \\
(U K)\end{array}$ & $\begin{array}{l}\text { PHENIX } \\
\text { (France) }\end{array}$ & $\begin{array}{l}\text { SUPER- } \\
\text { PHENIX } \\
\text { (France) }\end{array}$ & $\begin{array}{l}\text { SNR-300 } \\
\text { (Germany) }\end{array}$ & $\begin{array}{l}\text { MONJU } \\
\text { (Japan) }\end{array}$ & $\begin{array}{l}\text { CRBRP } \\
\text { (USA) }\end{array}$ \\
\hline $\begin{array}{c}\text { Total Mass of } \mathrm{Na} \text { in Secondary } \\
\qquad\left(10^{3} \mathrm{~kg}\right)\end{array}$ & & & 1500 & & & 570 \\
\hline Nominal Flow Rate $\left(10^{3} \mathrm{~kg} / \mathrm{s}\right)$ & 2.9 & 2.21 & 13.1 & 3.3 & & 4.8 \\
\hline $\begin{array}{l}\text { Steam Generator Outlet Tempera- } \\
\text { ture }(C)\end{array}$ & 370 & & 345 & & 320 & \\
\hline IHX Inlet Temperature (C) & & 343 & 345 & 328 & & 344 \\
\hline IHX Outlet Temperature (C) & & 543 & 525 & 521 & & 502 \\
\hline $\begin{array}{l}\text { Steam Generator Inlet Temperature } \\
\text { (C) }\end{array}$ & 530 & & 525 & & 515 & \\
\hline Water Temperature at SG Input (C) & & & 235 & & & \\
\hline Steam Temperature at Turbine (C) & & 510 & 487 & & & \\
\hline Water Pressure at SG Inlet (MPa) & & & 21.0 & & & \\
\hline Steam Pressure at Turbine (MPa) & & 16.3 & 17.7 & & & 10.0 \\
\hline Nominal Flow Rate $(\mathrm{kg} / \mathrm{s})$ & & & 1360 & & & 420 \\
\hline Primary Pump Location & Cold Leg & Cold Leg & & Hot Leg & Cold Leg & Hot Leg \\
\hline Intermediate Pump Location & Cold Leg & Cold Leg & & Cold Leg & Cold Leg & Cold Leg \\
\hline
\end{tabular}




\section{CRBRP HETEROGENEOUS CORE DESIGN}

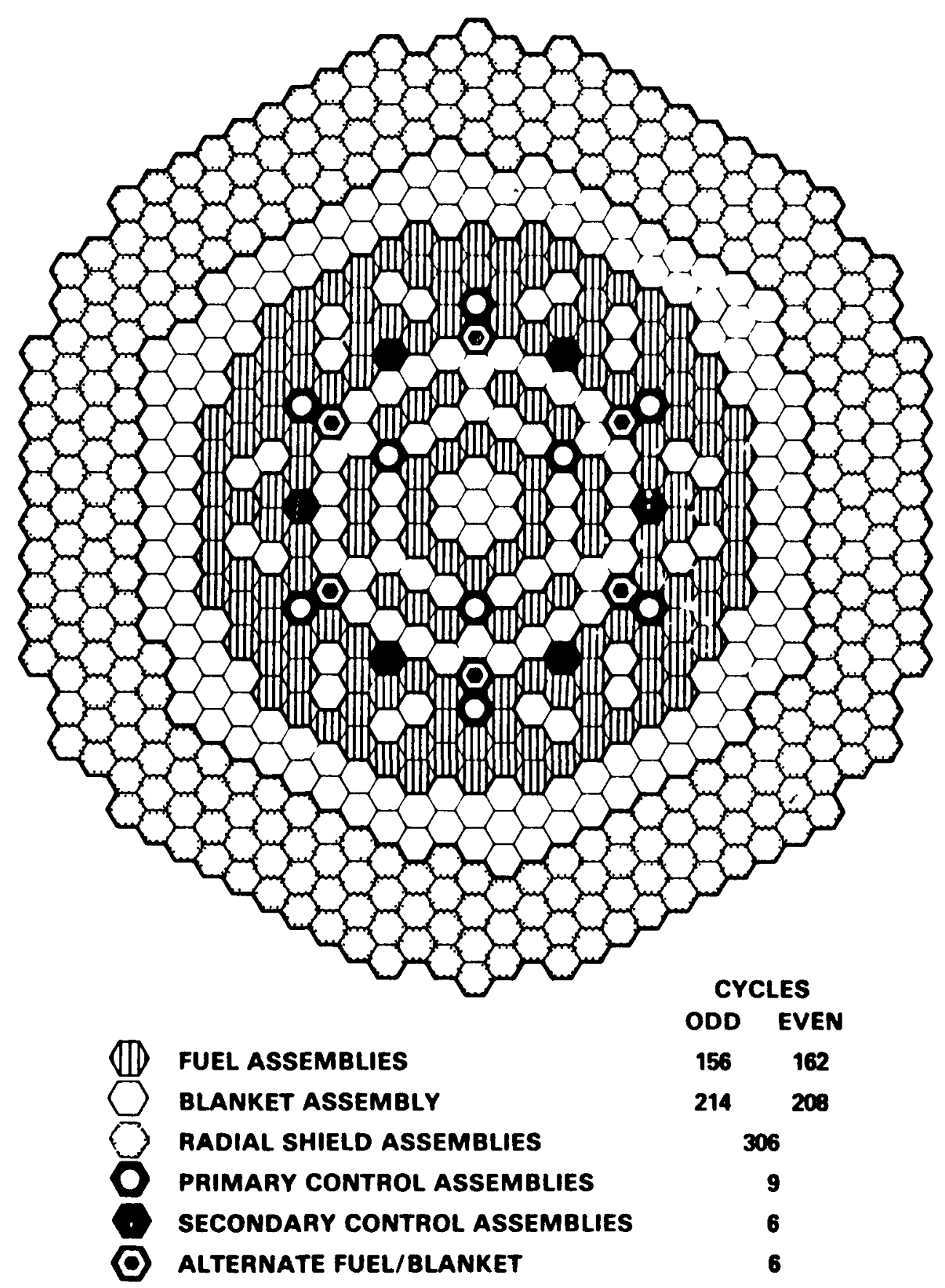

Figure 3 CRBR heterogeneous core design. 
hot sodium from the reactor vessel upper plenum through a $\mathrm{Na} / \mathrm{NaK}$ heat exchanger which pumps NaK through an air blast exchanger. This system requires integrity of the PHTS system as well as the availability of all three PHTS pony motors to provide sodium flow through the core. The entire heat transport system has been evaluated by Brookhaven National Laboratory and the findings are noted in a draft report [4].

The CRBR plant is protected by two independent and diverse shutdown systems either one of which is capable of effecting a shutdown. As an extra margin of safety, core-melt accidents (HCDAs) have been considered and structural and thermal margins beyond the design base (SMDBD and TMBDB) are provided. Adequacy of such margins against a range of HCDAs is being examined by the NRC and its consultants at Los Alamos National Laboratory and hence are not discussed here.

\subsection{PHENIX}

PHENIX is the world's first demonstration-size LMFBR plant. The design of this plant was based on the research done with RAPSODIE for fuel elements, and MASURCA and HARMONIE facilities for the pump and heat exchangers. It is interesting to note that the PHENIX plant is of the pool type, although considerable experience was gained from years of RAPSODIE (a loop-type design plant) operation. Construction work began in 1968 and the reactor went critical on August 31, 1973, followed by full power operation in 1974. The basic objectives were:

(1) The power rating should be sufficiently high to permit future extrapolation to 1000 MWe.

(2) The plant should be operable at different power levels to conduct experiments as well as to supply power to the electrical grid.

This plant (see Fig. 4) employs the pool-type design. This integrated reactor design provides for confinement in the case of incidents within the reactor block itself, thereby obviating the necessity of providing an impervious outer containment capable of withstanding high pressures. The components of this primary contaiment and the devices sealing it off from the atmosphere in the building are designed to withstand a pressure of five to six bars. The reactor building, of conventional design and constructed to contain an overpressure of 40 millibars (about $0.6 \mathrm{psig)}$, is a controlled leakage structure capable of confining normal and accidental contamination with control of exhaustion to the atmosphere. The key design parameters are listed in Table IV.

The safety design criteria for PHENIX are similar to those used in the SUPER PHENIX, and hence are not discussed here. Here, some discussions of the instrumentation and control systems are provided since the detailed level of instrumentation employed in PHENIX is indicative of a new generation of plants. 


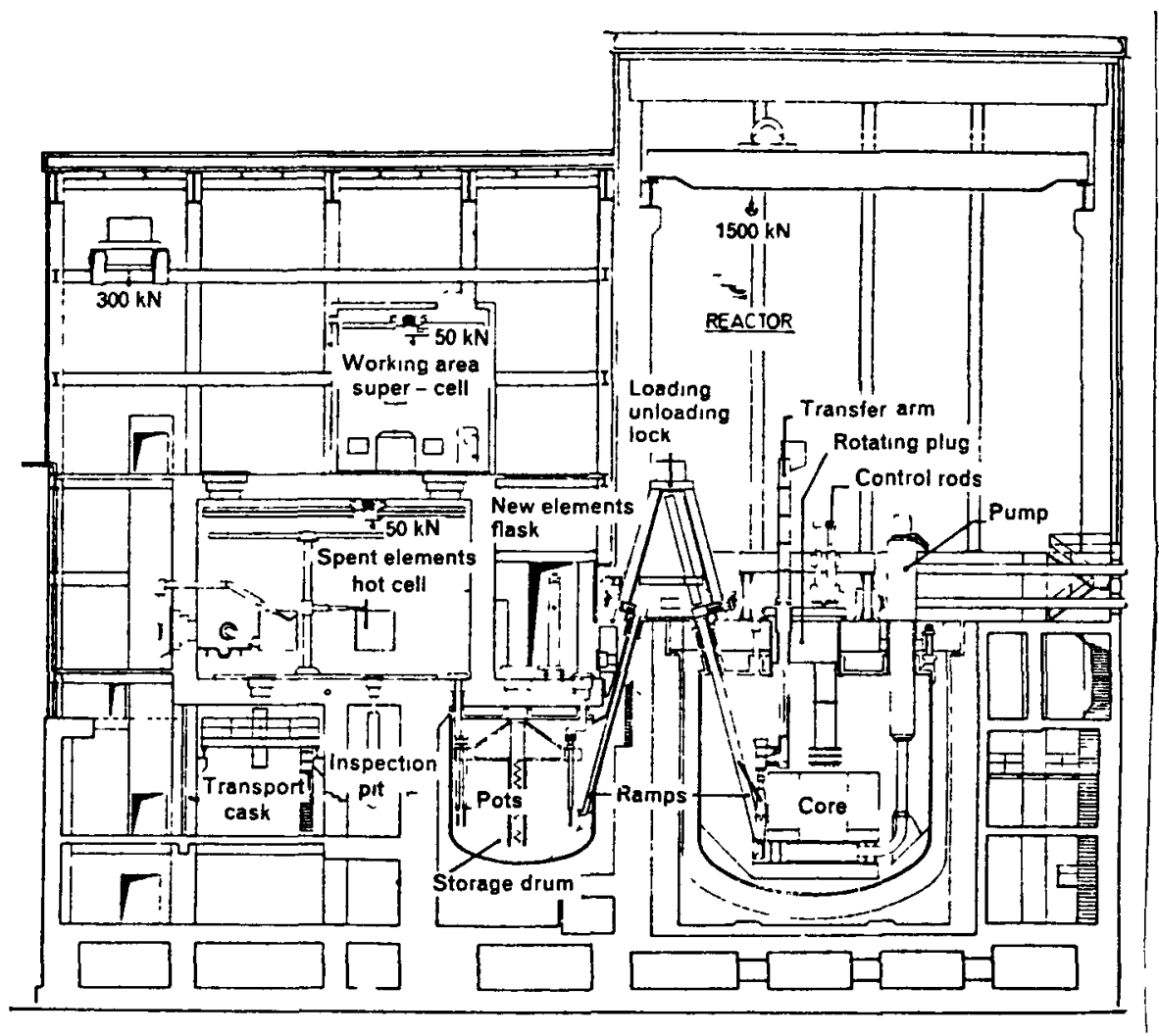

Figure 4 PHENIX plant layout. 


\section{Reactor Monitoring Systems}

The nuclear monitoring, manual control, and safety of the reactor are ensured by measuring the neutron flux over an eleven decade (from $3 \times 10^{-4}$ to $\left.3 \times 10^{7} \mathrm{n} / \mathrm{cm}^{2}-\mathrm{s}\right)$ dynamic range. This is carried out by employing (a) two pre-startup pulse channels, (b) three startup pulse channels, (c) three power channels, and (d) two controlling measurement channels. The reactivity meters afford an adequate solution for monitoring small changes in core reactivity. A change of $5 \mathrm{pcm}$ (i.e., $10^{-5} \Delta \mathrm{k} / \mathrm{k}$ ) in reactivity is considered as anomalous when at steady state power. Adjusting safety thresholds to this value imposes operating obligations and requires the use of an automatic inhibitor for this safety during normal reactivity changes (primary pump shutdown, under 3 seconds, voltage failures, control rod drops).

The thermal monitoring of the reactor is accomplished by monitoring all of the 121 fuel assemblies by a system comprised of two thermocouples for each assembly and two independent digital computers, each one processing temperature measurements of each assembly. These computers monitor any unusual temperature increases which may not be compatible with the reactor power and sodium flow rate for each assembly.

In addition, 12 sodium boiling detectors are located at the assembly outlet. These detectors listen to the level of ultrasonic noise, which is caused by implosion of the vapor bubbles when contacting colder regions.

2. The Failed Fuel Detection System

The thin cladding of the fuel pins and the high burn-up rate envisaged for the assemblies require that the integrity of the cladding should be monitored. The total monitoring facilities must ensure the three following functions: viz., to detect, identify, and locate the failed fuel assemblies. Therefore, the chosen devices involve sampling of sodium and the argon cover gas. Global detection (DND/G) of the iodine and bromine, which are delayed neutron-emitting fission products, is ensured by six samples of sodium taken from the vessel at the intake of the six intermediate heat exchangers. Fuel failures are 10cated by individual sodium sampling (DND/LRG) at the outlet of each fuel assembly.

Al 1 fuel assemblies are tagged with gaseous $\mathrm{Xe}$ and $\mathrm{Kr}$. The sampling of the argon cover gas reveals the location of the failed element.

3. Sodium Instrumentation

This instrumentation includes the electromagnetic flowmeters and the intermittent or continuous sodium level gauges. The sodium flowmeters on the PHENIX primary and secondary circuits are installed on large-diameter tubes. The continuous sodium level measurements are based on the principle of variation in the mutual inductance of two 
intercoupled windings submitted to the effect of the sodium level around them outside a protective sheath. A temperature-compensating device is associated with each measurement probe. The flowmeters and continuous sodium level measuring instruments are calibrated before being fitted in the power station.

4. Central Data Processing

This processing is carried out by two different circuits. One is assigned to the monitoring of nuclear boiler circuitry and the other to the electric generation plant circuitry and the electric power supply station's auxiliaries. These two computers do not share in the automated systems of the power station except for the failed fuel detection system.

5. Electric Power Supplies

The power station auxiliaries are supplied with electric power by a 50-MVA distribution transformer connected at the 20-kV level of the coaxial connection cables between the generator and the 20/225-kV transformer. A local 15-kV network provides emergency supply should the 225-kV grid fail, and as its power is restricted to 6 MVA, the power station is stopped in such a case.

Should these two sources fail, the standby auxiliaries are fed from two $2300 \mathrm{~kW}$ diesel-driven generators. Electric batteries keep the safety auxiliaries going, i.e., the primary sodium pumps auxiliary motors, the turbo-generator set emergency lubrication pump, and the various electric supplies required for the monitoring and control system ( $D C / A C$ inverters, etc.).

\subsection{SUPER PHENIX}

SUPER PHENIX (also known as the Creys-Malville Plant) is the world's first ful1-scale LMFBR. The construction of this multinational (51\% Electricite' de France, 33\% Ente Nazionale per 1 'Energia Elettrica, and 16\% Schnell-Bruter Kernkraftwerksgesellschaft) breeder reactor was started in 1977 . This plant is expected to go critical in 1983. The basic principles used in the design are:

(1) Continuity with PHENIX - Adhering to the PHENIX design as much as possible (primarily meant using the pool concept, and core design).

(2) Safety regulations - The Service central de Surete' des installations nucleaires very early (1975) decided a list of safety conditions that must be met. These are summarized in Section 3.2.1.

(3) Base load plant - This plant must be capable of operating on base load planned annual utilization of $75 \%$. 
This plant (see Fig. 5) employs the pool-type design, similar to the one used in PHENIX. This integrated design of the primary circuits offers the following advantages:

(1) Facilitates the confinement of the reactor assembly, and therefore of the primary active and contaminated sodium, as well as of the argon (cover gas) circuits,

(2) Provides large thermal inertia, allowing easy removal of the residual heat, and protects the structures against thermal expansion.

(3) Provides greater safety of cooling the core, even in the case of rupture of pipe connecting the pump with the vessel inlet.

The key design parameters are listed in Table IV.

The SUPER PHENIX plant has been considered, from the point of view of safety, in the same manner as any other nuclear plant in France. The licensing authorities provided guidelines in a basic document, entitled "Recommendations

Covering Safety Criteria for the 1200 MWe SUPER PHENIX Fast Neutron Plant," in 1973. Most of the major recommendations were noted earlier. The key safety features may be grouped under (a) Protective Measures and (b) Active Measures.

It appears that considerable emphasis was given to core surveillance. Any malfunction in cooling the core is detected by instrumentation on an individual assembly as well as the overall core surveillance. This is accomplished by (1) installation of two chromium/alumel thermocouples per assembly for all fissile and the first row of fertile assemblies, (2) installation of a fast response sodium-steel thermocouple per assembly, (3) sampling of sodium outlet of each assembly to detect fuel cladding failure location, (4) sampling of bulk sodium and argon to detect fuel cladding failure, (5) detection of sodium boiling by acoustic system, and (6) the measurement of sodium flow at primary pumps inlet. In addition there is a parallel computerized processing system.

The protection from aircraft and other missiles was based on a probabilistic analysis covering three ranges of missiles. Since the probability of impact of a light aircraft $(1700 \mathrm{~kg}$ with air impact speed of $100 \mathrm{~m} / \mathrm{s})$ on the reactor building is about $10^{-6}$ per year, a $1-\mathrm{m}$-thick concrete enclosure was provided for. The probability of a large aircraft (110 tons with an impact speed of $100 \mathrm{~m} / \mathrm{s}$ ) crashing on the reactor building is considered to be $10^{-8}$ per year which is very low and hence no specific protection against this type of missile is provided. The turbine-generators are located in such a way as to prevent missiles being propelled directly on the reactor building.

The magnitude of the design basis earthquake (termed as an operating basis earthquake, OBE, in our terminology) is obtained from historical data and the geological survey of the region. The value used for the maximum horizontal soil acceleration is $0.10 \mathrm{~g}$. Automatic shutdown is provided for. Subsequent operation after inspection is expected. The safe shutdown earthquake (SSE) is considered to be twice the acceleration of the OBE. The shutdown is also automatic for this level of acceleration and the plant is kept in a safe shutdown condition after such an event. 


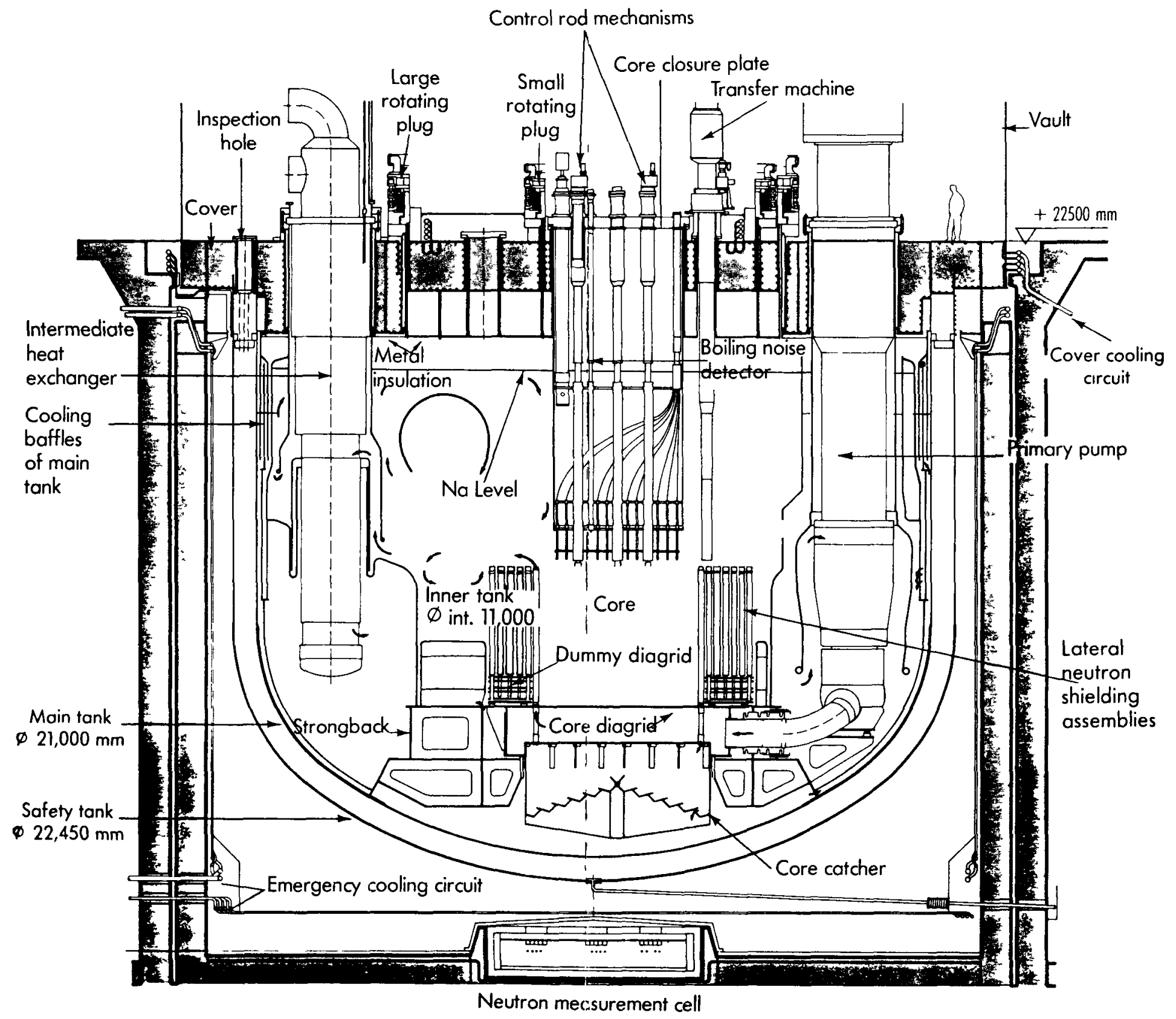

Figure 5 SUPER PHENIX plant layout. 
Three different shutdown systems are used in SUPER PHENIX . Neutronic shutdown is ensured by two independent systems comprised of ten or eleven absorber assemblies. The safety circuit is duplicated. The design is similar to the one used in PHENIX. These twenty-one rods are used for both control and safety. Four rods are sufficient to shut down the reactor. Furthermore, an additional shutdown system, comprised of three absorber rods, is also provided to enhance the reliability of the shutdown.

The decay heat is removed as follows:

(a) In nomal conditions, decay heat is dissipated through the four secondary loops, the four steam generators, and the appropriate water/steam circuits. Only one of the four secondary circuits together with its water circuit is able to reject the decay heat.

(b) Each secondary sodium loop is equipped with one sodium-to-air heat exchanger able to remove the decay heat even by natural convection. of the four sodium-air heat exchangers, only two are sufficient to maintain the primary sodium temperature without affecting plant safety.

(c) In the highly unlikely case that all four secondary sodium loops are not available, two emergency cooling circuits have been provided. These are water circuits located outside the safety tank and close to the concrete reactor cavity. These circuits operate continuously and each of them is designed to limit the primary bulk sodium temperature to $700^{\circ} \mathrm{C}$.

The containment of this plant is designed to accommodate the loss-of-flow accident with a further assumption that none of the 24 safety rods is inserted in the core. The following assumptions have to be made to culminate this event: (a) the loss of electrical power, (b) failure of the diesels to supply power, (c) none of the two banks of rods is inserted, and (d) none of the three additional backup control rods is inserted. (Note: SUPER PHENIX differs from the PHENIX in that the former incorporates the three additional backup control rods.) The likelihood of this event is thus classified as highly hypothetical, since even with the insertion of a single rod (out of 24) the power level attained could be removed by natural convection through the sodium-to-air heat exchangers, wi thout the sodium (primary) boiling temperature being reached. This accident leads to an ultimate mechanical energy release of $550 \mathrm{MW}-\mathrm{sec}(\mathrm{i} . \mathrm{e} ., 550 \mathrm{MJ}$ ). The performance of the containment has been checked for $800-M J$ mechanical energy release, and even with this energy release, the integrity of the primary containment (safety tank and vault) would be preserved.

\subsection{SNR-300}

SNR-300 breeder reactor (also known as the Kalkar nuclear power station) is a demonstration-size LMFBR under construction in the Federal Republic of Germany. This plant is a joint effort by the DEBENELUX countries (70\% FRG, 15\% Belgiuim, and 15\% the Netherlands). Although SNR-300 is a loop-type design, it does provide mitigating protection against the guillotine pipe rupture accident by incorporating the downcomer inside the reactor vessel. The construction work was started in April 1973; initial criticality is likely to be attained in 1985. 
A schematic of the reactor cell and vessel is shown in Fig. 6. Figure 7 shows the general plant layout and the containment system. The key design parameters are listed in Table IV. There are a number of important design features of this plant such as:

(a) The reactor core is designed for two types of fuel pins. The dimensions noted in Table IV represent the Mark IA fuel employing fuel pins of outer diameter of $6.0 \mathrm{~mm}$. Since it is economically advantageous to use larger diameter pins, the reload core (identified as Mark II) will employ $7.6 \mathrm{~mm}$ o.d. pins.

(b) The design of the reactor vessel allows for the inlet downcomer to be placed inside the vessel. This pipe is surrounded by liquid sodium. In the event of rupture of this pipe, the consequences of the reactor core will not be as severe as if this pipe were outside the vessel. In fact, the primary sodium temperature is not expected to reach its saturation value even for the "hot" channel.

(c) Six emergency decay heat exchangers are located inside the reactor tank. These heat exchangers, operating in parallel, transfer the decay heat to two forced convection air coolers via separate (nonradioactive) sodium loops equipped with electromagnetic (not centrifugal as used in the main heat transport circuits) pumps.

The design of the SNR-300 plant, along with its Plant Protection System, was influenced by the KNK-2 which itself was converted from the thermal test reactor KNK-1. The KNK-2 is a loop-type experimental facility (58 MWt, 20 MWe) in operation since 1977. The main emphasis at the SNR-300 from its start in 1970 was based on the strategy of assuring nuclear safety via accident prevention and not mitigation. This is because the prediction of the course of an accident is much more reliable than the quantitative description of destructive consequences. Furthermore, this philosophy gives the fullest possible protection to the invested capital. With these considerations in mind, it is helpful to discuss the shutdown system of SNR-300.

The SNR-300 plant is equipped with two independent and diverse shutdown systems, some key design parameters are noted in Table $V$ schematically shown in Figure 8. These and all other safety activators are controlled by two spatially and functionally independent PPS. There is no cross-connection between them. Both, however, overlap functionally with respect to their general tasks, especially in the protection of the integrity of the fuel assemblies.

\subsection{PFR}

The Prototype Fast Reactor (PFR) is Great Britian's first demonstration-size LMFBR built after a number of years of operation of a 60-MW DFR. The PFR has a design power output of $600 \mathrm{MWt}$ (250MWe). It serves as an intermediate step between DFR and the commercial unit. It is a pool-type LMFBR with the whole of the primary circuit contained in a tank suspended from the roof in a vault below ground level and surrounded by a close-fitting leak jacket. Inside the primary vessel and al so suspended from the roof is the support structure which carries the diagrid on which the fuel, blanket, and reflector assemblies are 


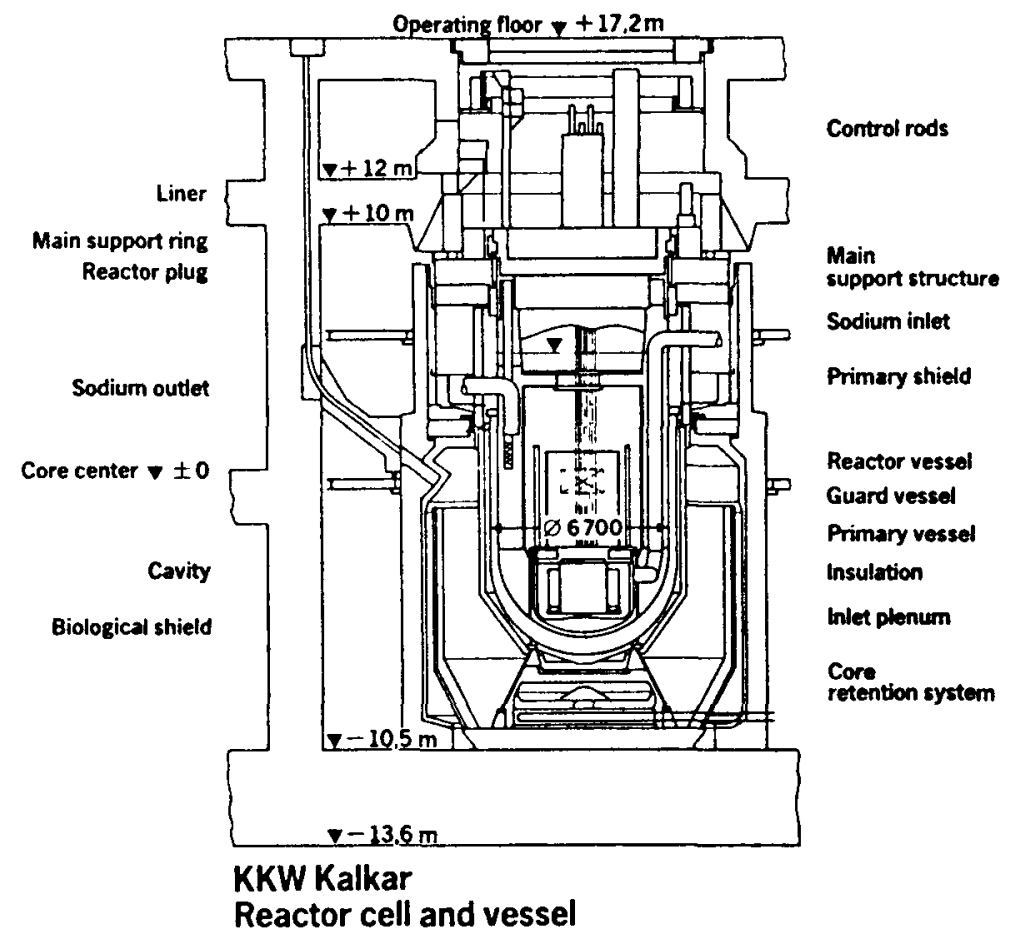

Figure 6 SNR-300 reactor vessel schematic. 


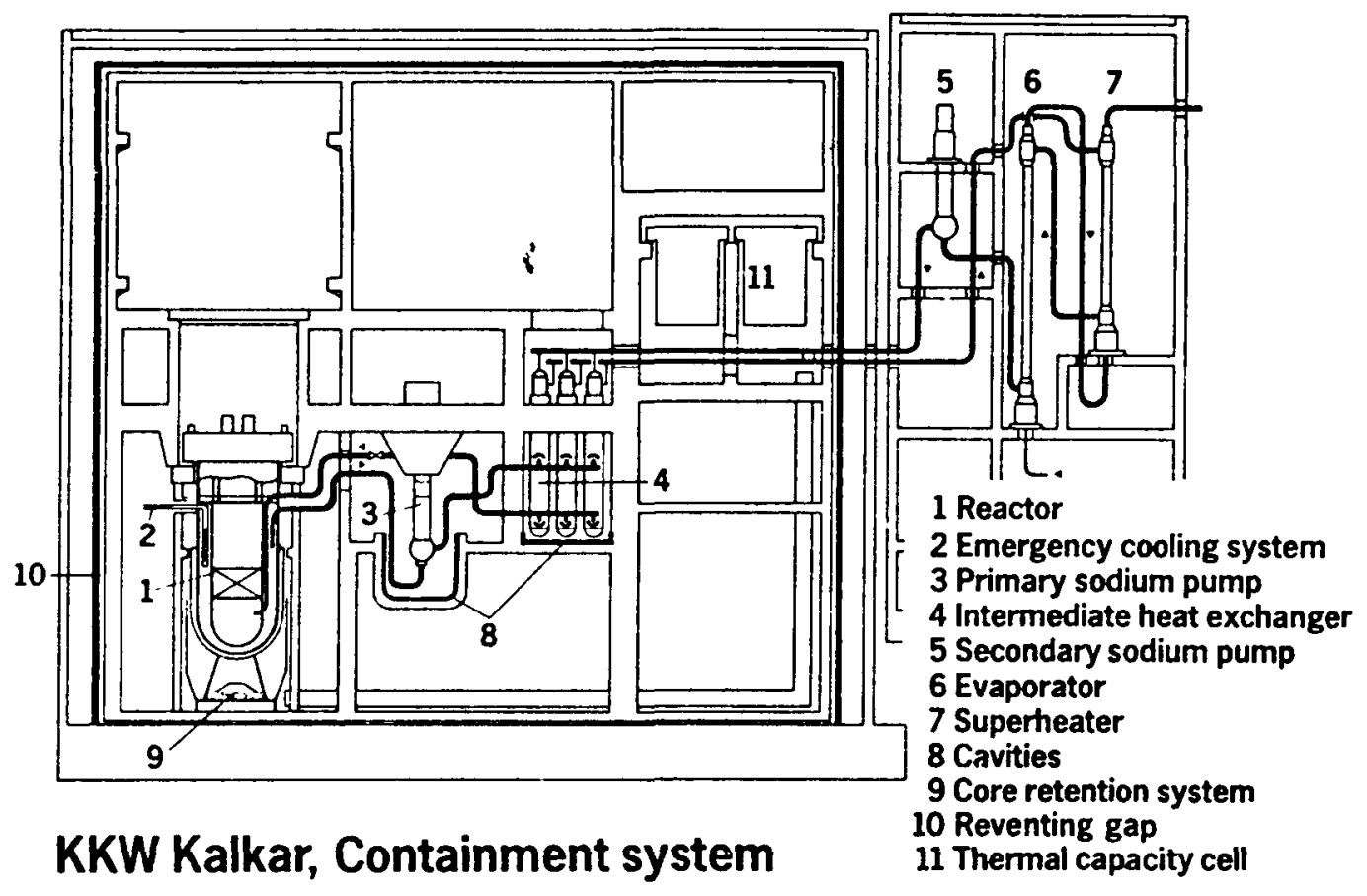

Figure 7 SNR-300 plant layout. 
Table $V$. Comparison between the first and second shutdown systems of SNR-300

\begin{tabular}{|c|c|c|}
\hline Parameter & 1st Shutdown System & 2nd Shutdown System \\
\hline $\begin{array}{l}\text { 1. Accident reactivity } \\
\text { compensation }\end{array}$ & Identical amount & Identical amount \\
\hline 2. Sensing & Diverse and redundant & $\begin{array}{l}\text { Diverse and redundant } \\
\text { but different set points }\end{array}$ \\
\hline 3. Logic System & Different manufacturer & Different manufacturer \\
\hline 4. Absorber & Rigid rod bundle & $\begin{array}{c}\text { Flexible (three rod } \\
\text { bundles) }\end{array}$ \\
\hline $\begin{array}{l}\text { Standby fission } \\
\text { Insertion mode }\end{array}$ & $\begin{array}{l}\text { Above core } \\
\text { Free drop by gravity }\end{array}$ & $\begin{array}{l}\text { Below core } \\
\text { Pulled upwards by } \\
\text { tensioned springs }\end{array}$ \\
\hline 5. Scram release & $\begin{array}{l}\text { Indirectly by scram } \\
\text { magnet opening a } \\
\text { mechanical scram } \\
\text { clutch }\end{array}$ & Directly by scram magnet \\
\hline 6. Centering & $\begin{array}{l}\text { Centering tube held } \\
\text { down by spring forces }\end{array}$ & $\begin{array}{l}\text { Centering tube held down } \\
\text { by spindle }\end{array}$ \\
\hline $\begin{array}{l}\text { 7. Max tolerable } \\
\text { misal ignment between } \\
\text { axes of absorber and } \\
\text { plug penetration }\end{array}$ & $26 \mathrm{~mm}$ & $40 \mathrm{~mm}$ \\
\hline $\begin{array}{l}\text { 8. Max tolerable angle } \\
\text { between absorber } \\
\text { guide tube and con- } \\
\text { nection rod }\end{array}$ & $1.3^{\circ}$ & $2.2^{\circ}$ \\
\hline
\end{tabular}




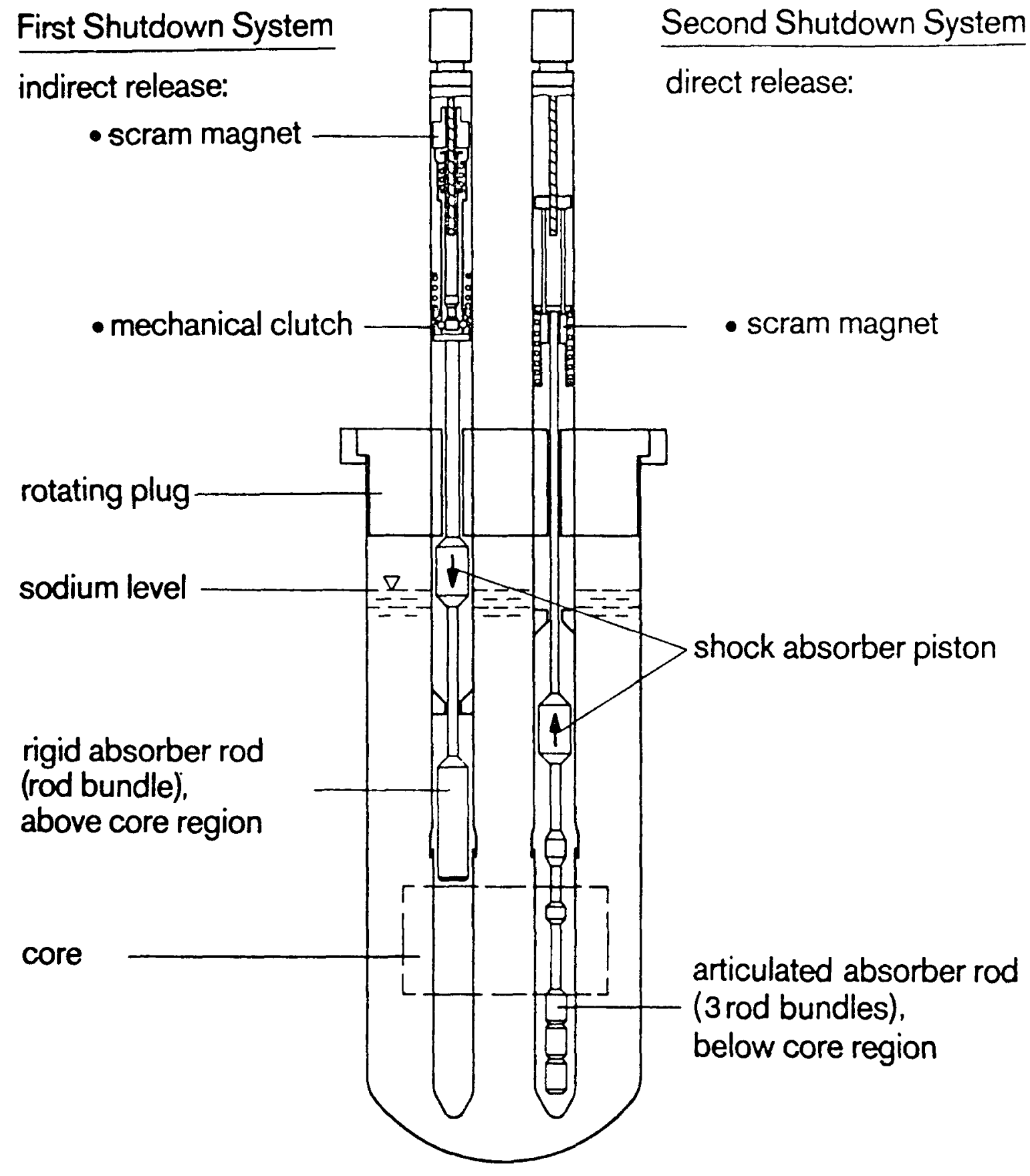

SNR-300: SHUTDOWNSYSTEMS

Figure 8 SNR-300 shutdown system design. 
assemblies are mounted. There are three intermediate heat transport circuits, each connected with two intermediate heat exchangers in parallel. The three centrifugal pumps are located in the cold leg of sodium. This reactor achieved criticality on August $31,1973$.

Some of the important design parameters are noted in Table IV. The arrangement of components within the main reactor tank is shown in Figure 9 . As is common with all pool-type designs, there is no penetration of the tank below the sodium coolant level which thus assures the highest possible integrity against loss of coolant. The PFR safety principles are:

1. Loss of coolant from the core is discounted on the basis of rigorous design of the primary tank with all penetrations through the roof, and provision of a completely separate leak jacket. The arrangement of the primary circuit and leak jacket is such that they are contained in a concrete vault below ground level.

2. Temperature transients, due to coolant flow failure, are controlled by tripping the reactor (guaranteed by a multiplicity of trip parameters) and provision of sufficient pump inertia to restrict the maximum temperature to acceptable values. The larger volume of sodium in the primary tank is directly cooled at all times by a number of independent natural convection loops.

3. Reactivity transients are controlled by limiting the maximum rate of reactivity insertion, assuming all absorber is moved simultaneously, to a value such that the transient can be terminated by reactivity trips without exceeding fuel-failure temperatures.

4. Propagation of certain subassembly faults could not be ruled out and therefore the inherent strength of the primary tank, leak jacket, and vault has been exploited to provide a containment system. A series of model tests has demonstrated the ability of the containment arrangement to withstand a considerable explosive energy release.

The reactor hall is a low-pressure containment building, designed to withstand a relatively modest internal pressure of $20 \mathrm{in}$. of water with a reasonable low leak rate, and provided with a chemical cleanup plant. The core design provides for extensive use of fuel-failure detection equipment employing delayed neutron monitors, in addition to subassembly exit thermocouples and neutron flux instrumentation. Special provisions, in the form of a specially cooled structure below the core support plates, have been made to hold a disrupted or partly melted core within the primary vessel, in the unlikely event of this situation.

A significant aspect of the PFR fuel design is the location of the fission gas plenum. In PFR, the fission gas plenum is located at the bottom of each pin, in contrast with almost all other plants. This design provides for a lower likelihood of accidental gas release since the plenum temperature is essentially at the cold sodium temperature. On the other hand, in the event of leaks due to fabrication flaw or other causes, the released fission gas will have to escape through the heat-producing region. This will result in (1) a 


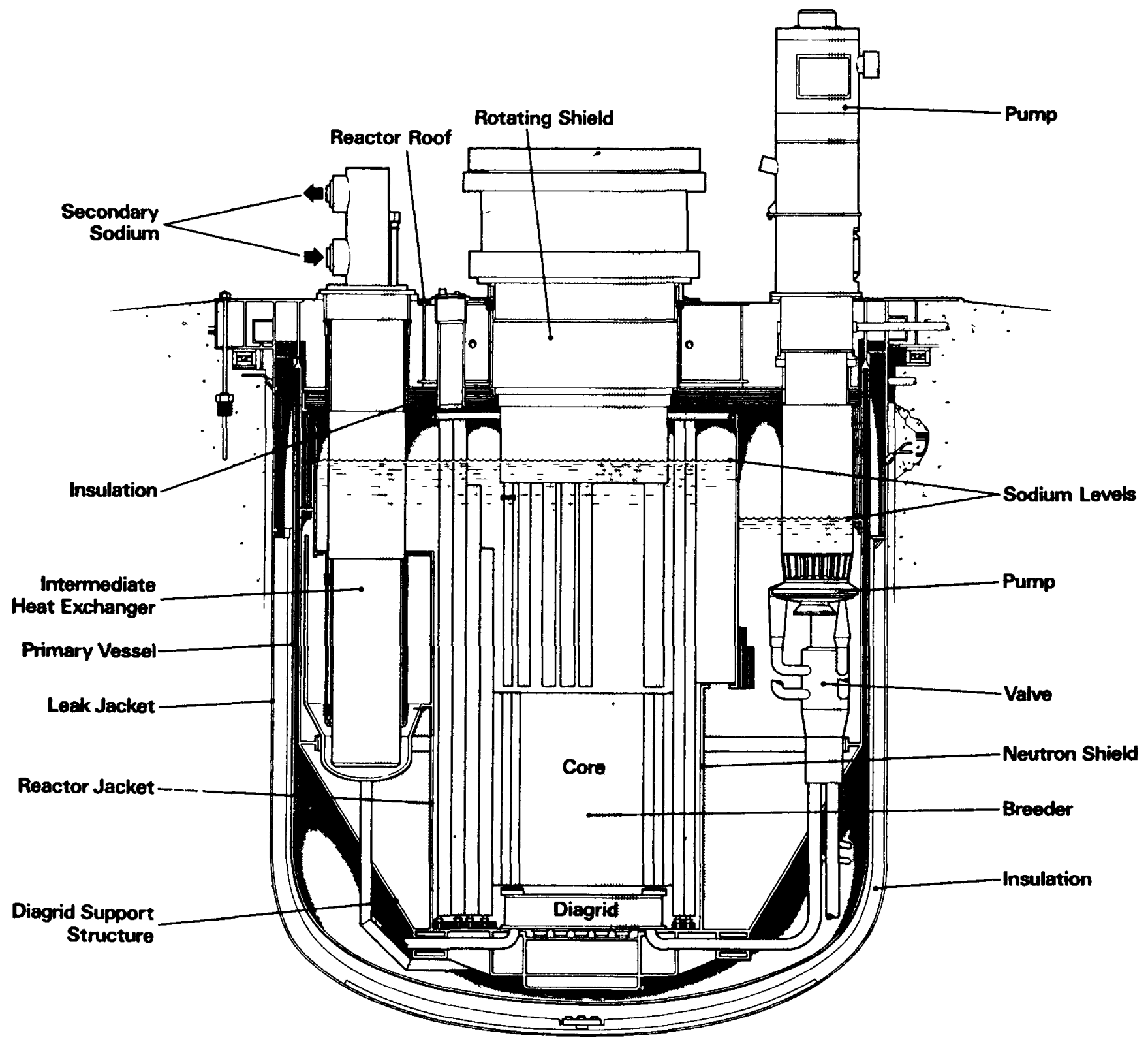

Figure 9 PFR reactor tank layout. 
temporary gas blanketing of the heated section causing additional overheating, and (2) a reactivity insertion due to sodium void thus caused.

\subsection{MONJU}

MONJU is a prototype fast breeder reactor under construction in Japan. It succeeds the experimental fast reactor JOYO which has been in operation since 1977. MONJU is a loop-type LMFBR with thermal power output of 714 MW. The key design parameters are noted in Table IV. The reactor vessel and the primary coolant system are situated in the containment building. The secondary system, steam generators, turbine, and electrical system are located in the auxiliary buildings. The containment building is made of a low leakage steel and houses the reactor and primary coolant system.

Guard vessels surround the reactor vessel, the pumps, and the intermediate heat exchangers. All elevated primary pipings are surrounded by a guard pipe. Thus, in the event of any breach in the coolant boundary, the reactor core is assured to be covered (this does not preclude any damage to the fuel and blanket assemblies). 


\section{DISCUSSION}

This section is intended to discuss (1) design criteria used, (2) design basis accident definitions, and (3) important observations on the accident analyses. Such a discussion for the CRBR plant, which is under review for the construction permit, is taken largely from the applicant's PSAR and various information exchange meetings held over the past year between the applicant and the NRC's CRBR Program Office. For foreign plants this information was hard to get. A complete point-by-point comparison is thus not possible.

\section{$3.1 \quad$ CRBR}

\subsubsection{Acceptance Criteria}

The applicant, in conjunction with the U.S. Department of Energy, has developed a set of acceptance criteria for LMFBRs in general and for the CRBR plant in particular. All incidents are first categorized and the acceptable severity levels are defined (see Table VI). The acceptance criteria used by the applicant are given in Table VII.

The acceptance criteria noted in Table VII are to be applied for event termination due to the primary shutdown system. If the primary shutdown system is postulated to fail, then the next higher level of damage is allowed for the event termination with the secondary shutdown system. The rationale is that failure to actuate the primary shutdown system is a low probability event so that the combined probability of the event occurring and the secondary shutdown system activation being required is much lower than the probability of the event occurring. Thus the resulting damage severity limits for either the primary system or the secondary system only functioning are noted in Table VIII.

\subsubsection{Design Basis Accident and Analyses}

In a previous section ( $\mathrm{Sec} .1 .4$ ), the applicant's position on the design basis accidents was discussed. All of the 67 SFAC events and the five additional events for a total of 72 events have been grouped two ways: (a) in terms of their classifications and (b) in terms of their analyses. The classification of these events basically defines the acceptance criteria.

The events considered in the CRBR are grouped as follows:

\section{(a) Reactivity Insertion Events}

1. Uncontrolled control rod assembly withdrawal from a subcritical condition assuming the most unfavorable reactivity conditions of the core and reactor coolant system (1).

2. Uncontrolled control rod assembly withdrawal at power assuming the most unfavorable reactivity conditions of the core and reactor coolant system which yield the most severe results (hot at zero power, full power, etc.) (2). 


\section{Table VI. Event classification and damage severity limits for CRBR}

Event Classification

$$
\text { Mechanical Design }
$$$$
\text { (Chapter 4) }
$$

Norma 1:

Any condition of system startup. design range operations, hot standby, or shutdown other than an upset, emergency, faulted or testing conditions.

Upset:

Any abnormal incident not causing a forced outage or causing a forced outage for which the corrective action does not include any repair of mechanical damage.

Emergency:

Infrequent incident requiring shutdown for correction of the condition or repair of damage in the system. No loss of structural integrity.

Fauited:

Postulated event and consequences where integrity and operability may be impaired to the extent that considerations of public health and safety are involved.
RDT Standard C-16-1

Normal Operation:

Normal operation includes steady power operations and those departures from steady operation which are expected frequently or regularly in the course of power operations, refueling, maintenance, or maneuvering of the plant.

Anticipated Faulted:

An off-normal condition which individually may be expected toroccur once or more during the plant lifetime.

Unlikely Faulted:

An off-normal condition which individually is not expected to occur during the plant lifetime; however, when integrated over all plant components, events in this category may be expected to occur a number of times.

Extremely Unlikely Faulted:

An off-normal condition of such extremely low probability that no events in this category are expected to occur during the plant lifetime, but which nevertheless represents extreme or limiting cases of failures which are identified as design bases.
Severity Level

RDT Standard C-16-1

No Damage:

No damage is defined as 1) no significant loss of effective fuel lifetime; 2) accomodations within the fuel and plant operating margins without requiring automatic or manual protective action; and 3) no planned release of radioactivity.

Operational Incident:

An operational incident is defined as an occurrence which results in 1) no reduction of effective fuel lifetime below the design values; 2 ) accommodation with, at most, a reactor trip that assures the plant will be capable of returning to operation after corrective action to clear the trip cause; and/or 3) plant radioactivity releases that may approach the 10CFR2O guidelines.

Minor Incident:

A minor incident is defined as an occurrence which results in 1) a general reduction in the fuel burnup capability and, at most, a small fraction of fuel rod cladding failures;

2) sufficient plant or fuel rod damage that could preclude resumption of operation for a considerable time and/or 3) plant radioactivity releases that may exceed 10CFR20 guidelines, but does not result in interruption or restriction of public use of areas beyond the exclusion boundary.

Major Incident:

A major incident is defined as an occurrence which results in 1) substantial fuel and/or cladding melting or distortion in individual fuel rods, but the configuration remains coolable; 2) plant damage that may preclude resumption of plant operations, but no loss of safety functions necessary to cope with the occurrence; and/or 3) radioactivity release that may exceed the 1OCFR20 guidelines but are well within the 10CFRI00 guidelines. 
Table VII. Acceptance criteria for preliminary safety evaluation for CRBR

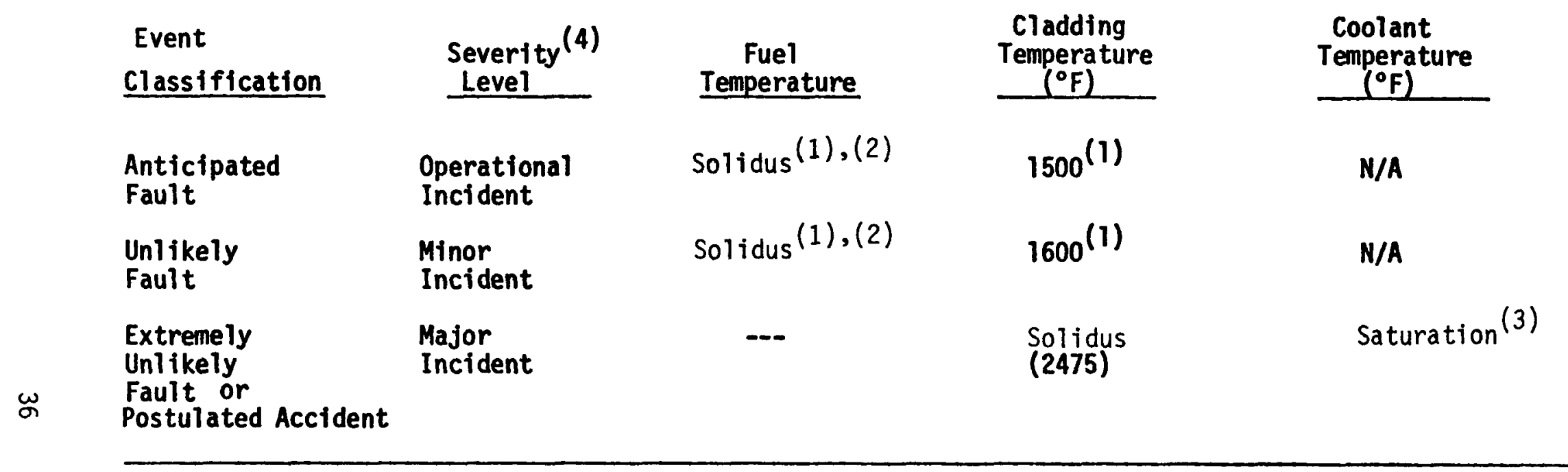

NOTES:

(1) For temperatures in excess of these values, transients shall be assessed using mechanical design procedures and design limits of Chapter 4.2 of CRBR PSAR.

(2) No fuel melting at existing conditions.

(3) No sodium boiling at existing pressure.

(4) Applicable "Event Class" or "Severity Level" is based on Primary Shutdown System action - For Secondary System Shutdown see Table 4.2-35. 
Table VIII. Primary and secondary shutdown system damage severity limits for CRBR

\begin{tabular}{|c|c|c|c|c|c|c|}
\hline \multirow{2}{*}{$\begin{array}{c}\text { Event } \\
\text { Classification }\end{array}$} & \multicolumn{6}{|c|}{ Damage Severity Limit } \\
\hline & \multicolumn{3}{|c|}{ Primary System Only Functioning } & \multicolumn{3}{|c|}{ Secondary System Only Functioning 1} \\
\hline $\begin{array}{l}\text { Unlikely } \\
\text { Faults }\end{array}$ & Solidus & $1600 \mathrm{~F}$ & $N / A$ & -- & $\begin{array}{l}\text { Sol idus } \\
(2475 \mathrm{~F})\end{array}$ & Saturation 2 \\
\hline $\begin{array}{l}\text { Extremely Un- } \\
\text { likely Faults }\end{array}$ & $-\cdots$ & $\begin{array}{l}\text { Sol idus } \\
(2475 \mathrm{~F})\end{array}$ & Saturation ${ }^{2}$ & & a Design Bas & $s^{3}$ \\
\hline
\end{tabular}

(1) Failure of the primary system to scram when required for an anticipated fault is defined as an extremely unlikely event (fault condition). However, the damage severity limit for the secondary shutdown system is conservatively specified to assure fuel pin integrity even for the concurrent anticipated fault and failure of the primary shutdown system.

(2) No sodium boiling at existing pressure.

(3) Combined probability of two independent failures (extremely unlikely fault and failure of primary control rod system) is exceedingly low and not appropriate as a design basis. However, as an exception, the following concurrent events are being used as a design basis: a) loss of offsite power resulting from a safe shutdown earthquake (with a consequent reactivity insertion of $60 \notin$ ) and b) failure of the primary control rod system. With these concurrent events, the secondary shutdown system shall be capable of shutting down the reactor without exceeding major incident limits (i.e., no sodium boiling and the cladding below its solidus temperature). 
3. Control rod misoperation or sequence of misoperations (3).

4. Start-up of an inactive reactor coolant loop or recirculating loop at incorrect temperature (5).

5. Maloperation of reactor plant controllers (10).

6. The spectrum of rod ejection accidents (17).

7. Gas bubbles passing through the core (34).

8. Inadvertent drop (delatching) of a single control rod (38).

9. Failure of core clamping mechanism (41).

10. Unknown stuck control rod (47).

(b) Undercooling Events

11. Partial and total loss of reactor coolant flow including trip of pumps and pump seizures (4).

12. Loss of normal and/or emergency feedwater flow (6).

13. Loss of all AC power to the station auxiliaries and loss of emergency diesel generators (station blackout) (7).

14. Loss of intermediate coolant flow (8).

15. Loss of coolant accidents resulting from the spectrum of postulated piping breaks within the reactor coolant system (12).

16. Spectrum of postulated intermediate coolant system piping breaks inside and outside of the containment (13).

17. Loss of heat sink (22).

18. Turbine trip with coincident failure of tubine bypass valves to open (23).

19. Failure of a few steam generator tubes (30).

20. Failure of steam dump system (35).

21. Inadvertent closure of either reactor coolant valves or intermediate coolant valves (36).

22. Spurious reactor trip (37).

23. Plugging of reactor overflow line (40).

24. Accidental opening of valves to a drained isolated loop (42).

25. Large leak (rupture) in steam or feedwater piping (43). 
26. Loss of normal shutdown cooling system (48).

27. Simultaneous leak of reactor overflow tank (49).

28. Heat removal greater than heat generation due to (a) feedwater system malfunctions, (b) a pressure regulatory failure, or inadvertent opening of a relief valve or safety valve, and (c) a regulating instrument failure (9).

(c) In-core Local Failure Events

29. Inadvertent loading and operation of a fuel assembly in to an improper position (14).

30. Local brockages of a few subchannels within a fuel subassembiy (27).

31. Core flow maldistribution due to fuel loading error (33).

32. Gas bubbles passing through the core (34).

33. Enrichment error in fuel assembly (44).

34. Misloaded fuel assembly (45).

35. Blocked coolant flow to control rods (66).

(d) Fuel-Handling and Storage Events

36. Fuel-handiing accident (18).

37. Dropped fuel assembly (46).

38. Inadvertent closure of floor valve on canister during fuel handling (50).

40. Loss of site power during fuel handling (52).

41. Fuel-handling machine jams (53).

42. Leak in fuel storage vessel (54).

43. Failure of single active component in fuel storage cooling system (55).

44. Failure to seat fuel assembly properly (56).

45. Inadvertent opening of floor valve with shield plug removed and fuel-handling machine not in place (57).

46. Leak in fuel canister (58). 
47. Inadvertent opening of fuel handling machine valve during transfer (59).

48. Attempt to insert a fuel assembly into occupied position (60).

49. Collision of fuel-handling machine with control rods (61).

50. Dropping shipping cask from maximum possible crane height (62).

51. Collision between fuel-handling machine and crane (63).

52. Loss of all power to fuel-handling machine (64).

53. Removal of jammed fuel assembly (65).

(e) Sodium Spills and Fires

54. Internal and external events such as major and minor fires, flood, storms, or earthquakes (11).

55. Loss of coolant accidents resulting from the spectrum of postulated piping breaks within the reactor coolant system (12).

56. Spectrum of postulated intermediate coolant system piping breaks inside and outside containment (13).

57. Intermediate coolant system fire (67).

(f) Other Events

58. Waste gas decay tank leakage or rupture (15).

59. Small spills or leaks of radioactive material outside containment (19).

60. Fuel cladding failure combined with intermediate heat exchanger and steam generator leaks (20).

61. Loss of one (redundant) DC system (24).

62. Turbine trip with failure of generator breaker to open (25).

63. Loss of instrument air system (26).

64. Leak in control rod drive housing (28).

65. Inadvertent release of oil in pump seal into sodium (29).

66. Leaks in intermediate heat exchanger (31).

67. Abnormally high or low cover gas pressure (32).

68. Failure of reactor vessel cover seal (39). 
Note that the numbers after the identification of events corresponds to the numbering used in the SFAC list (Table II). The remaining four events are non-events. All of these events have been analyzed in the PSAR where they are shown to meet the acceptance criteria.

\subsection{SUPER PHENIX}

\subsubsection{Design Basis Accidents and Requirements}

The Nuclear Safety Department of CEA provided in 1972 the following recommendations for the safety criteria for SUPER PHENIX in order to give safety design guidance to the constructors at the pre-design stage. The final form of a 40-page typewritten document was presented officially at the end of 1972 after consultation with all the participants in the program and several editions were made. The safety guidance document was approved in February 1973 by the licensing authority under the title of: "Recommendations for Safety criteria Applying to the 1200 MWe SUPER PHENIX Fast Power Station."

As background, it is important to note that the safety design bases are recommendations only. Secondly, these criteria have been written in terms of general principles. Thirdly, these criteria were established on the following:

(1) First and foremost, recent French knowledge of sodium fast reactors based on more than 20 years of experience, especially on RAPSODIE and PHENIX. PHENIX, in particular, has been a constant reference and results of its startup, power rise, and full power operation served to confirm some major safety options such as core-monitoring instrumentation performance, natural circulation, emergency cooling, etc.

(2) International experience, especially from the U.K., U.S.A., and Germany. In particular, although a direct transposition of USAEC LWR criteria was not possible, some of them have been used or adapted.

(3) This station will be a prototype, operated on a site situated in a low-population density area. One must al so note that the reactor will be of a pool type and some of the recommendations are strictly linked with this concept.

This safety guidance document has three main chapters: Chapter One deals with general design criteria, Chapter Two is a list of the accidents that must be assessed in the safety analysis, and Chapter Three gives detailed design principles of protection against the accidents listed, in terms of methods for prevention, detection, and action to cope with them or to limit their consequences if an accident reaches further stages.

Because of the unavailability of this document in the U.S.A., the following seven points - protective system, primary system, core accidents prevention, whole-core accident and containment, sodium fires protection, seismic design, and external missiles protection - are briefly discussed. 
1. Protective System

Important factors about design basis requirements for this system are:

- Two systems are recommended, a main system and a backup system based on a different principle. For the main system, the following requirements are given:

- It must be divided into two completely independent systems, each one actuating half of the control rods. This includes geographic separation of all circuits, connections, and power supplies.

- The reactor must be able to be scrammed in less than one second and maintained subcritical in the cold condition assuming simultaneous failure to trip of one system and of one rod of the other system.

- The protective system and the core reactivity must be designed such that with either a single rod ejection, or complete and uncontrolled withdrawal of one group of rods at maximum possible speed (one group being the maximum that can be actuated one at a time), reactor trip must safely control the transient, or if the trip faiis, technological limits on fuel pins will not be reached (that does not mean, of course, that the specified limits for normal operation will not be reached).

\section{Primary System}

This part refers to a pool-type concept for which the whole volume of the primary sodium, including auxiliary systems, is entirely contained inside a single primary containment without any external pipes. (This was almost the case for PHENIX except for auxiliary systems; for SUPER-PHENIX, everything is designed to be integrated).

The various required characteristics are divided into two main categories referring to the containment function of the primary system and to its cooling function.

a) In terms of containment function:

- Constructive dispositions will be taken in order to make accidental or spurious draining out of primary system impossible.

- A safety vessel will be provided around the main vessel, designed to al low in-service inspection of the main vessel, and be such that in case of a failure of the main vessel, the sodium level will be higher than the core and IHX inlet levels, thus allowing decay heat removal by natural circulation.

- The safety vessel, its upper closure structures, and structures around them must safely contain the consequences of whole-core accidents (we will come back to this point later). 
b) In terms of cooling function:

- Natural circulation must be possible in the whole primary system (this is a very important advantage of the LMFBR system in its ability to ensure emergency decay heat removal by simple and static means based on natural convection).

- Decay heat removal system will be ensured by several independent and redundant paths with, in case of complete loss of the normal system (including complete loss of power supply for forced convection), an emergency system completely independent. SUPER-PHENIX is being designed in this regard with very large inertia systems on primarypump power supply aiming, at the limit, at avoiding damage to fuel in case the pumps run down without a scram.

- An emergency cooling system external to the primary containment, independent of any system connected with primary sodium forced convection and away from the influence of direct mechanical consequences of accidental core-disruptive accidents. It will consist of a water system, over-designed and separted in several independent loops, used in normal operation to cool the concrete around the primary containment. Such a system, which is static, permanently tested and independent of primary system internals is a major safety characteristic.

- Besides, an internal core catcher is under design.

\section{Core Accident Protection}

Fast reactor cores are sensitive to cooling defects due to high power densities that develop in a compact geometry which is divided into small coolant channels. The cooling-defect-type accident must be prevented and detected not only because of the immediate consequences, but also because it is possible that theoretically, through a propagation process, a whole-core accident might be initiated.

\section{a) Prevention}

In addition to the important classical requirements for quality control of all components, we list the following design requirements to prevent occurrence of cooling accidents at core level:

- Hydraulic holddown of subassembly (S/A).

- Mechanical systems to physically prevent S/A positioning in wrong flow positions.

- S/A inlets designed to prevent complete flow blockages, with several large lateral feeding holes around a cylinder. 
- Prohibition of reactor operation with failed fuel that could release solid particulates of oxides into the sodium in order not to risk heating local blockages inside S/A. This means that permanent individual delayed-neutron detection (DND) must be provided and therefore a sodium sampling system is necessary for each S/A. This also means that the characterization of different modes of fuel failure must be known since it would be too large a penalty to for-bid any kind of operation with failed fuel.

b) Core Monitoring System

Considerations of the nature of potential risks and of the importance of the problem to be solved leads to the concept of a core monitoring system capable of early detection of any cooling disturbance and of tripping the reactor prior to propagation towards an irreversible situation.

This system must be based, for obvious complementarity and redundancy reasons, on individual S/A detection, global core detection, and correlation between the two types of signals.

4. Whole-Core Accident and Containment

When the recommendations were written, the mechanistic analyses of possible whole-core accidents were not undertaken. It was stated at that time that the double potential risk of prompt nuclear excursion in case of large core melting, and of subsequent sodium-fuel interaction had to be taken into account for the dimensioning of the primary and secondary containiment in a conservative way, even quite arbitrarily and regardless of the initial causes.

In continuity with PHENIX, the project has taken a working hypothesis of a coherent gravity compaction of the core leading to a $60 \$ / \mathrm{s}$ ramp rate. The containment designed on this basis consists of a primary containment (main and safety vessels) with a reactor cover, in addition to a tight, resistant, metallic dome above the roof. This dome serves as the primary containment boundary in the case of primary sodium leakage around large component penetrations through the roof of more than 1.1 tons of primary sodium. It also protects the roof from external missiles and secondary sodium fires.

\section{Sodium Fires}

Primary and secondary sodium fires have quite different characteristics:

- Primary sodium fires are always radioactive and may happen under the form of spray fires which give the worst thermodynamic consequences (in terms of pressure and temperature for a given mass of sodium reacting with air) if they result from an expulsion through roof penetrations following a core explosion. In that case, however, containment and limitations of masses of sodium that could be released in non-inerted partsof the reactor are relatively easy to achieve.

- Secondary sodium fires are not radioactive and are much more likely to be pool-type fires, but the limitation of the masses that could react with air is quite difficult. 
Recommendations, therefore, are different according to the type of fire. Because of the radioactive character of primary fires, it is necessary to have at least three tight and resistant barriers between primary sodium and air at all times, and to confine any radioactive sodium circuits in inerted cells. For secondary sodium fires, there are two general criteria: First, the primary system must be protected from all secondary fires. Secondly, large secondary $\mathrm{Na}$ fires at definite sensitive points or components such as pipes, pumps, valves, tanks, and steam generators must not be allowed to spread and cause severe damage to other sensitive parts of the plant. These recommendations are in addition to the classical requirements for leaks and fire detection and alarm systems wherever sodium is present.

\section{SEISMIC DESIGN}

Seismic design requirements entail taking into account a given design earthquake. The plant must not suffer any damage that would require any major repair. Furthermore, for an earthquake of magnitude one degree higher than the above noted level, the nuclear safety of the plant must be guaranteed.

\section{MISSILES \\ a. Internal Missiles}

In addition to the general recommendation protection against missiles internal to the plant, two particular points are stated with specific criteria: (1) there must be an antimissile protection around the inertia wheels of primary pumps, (2) the axis of the turbine must be perpendicular to the main axis of reactor and plant building in order that it be protected against rotor turbine rupture consequences.

\section{b. External Missiles}

A probability analysis of aircraft-crash risk showed that the SUPER PHENIX site is outside any airport landing or approach zone, and consequently only the crash of light planes up to 12,500 lbs. must be taken into account. The probability of such an accident is slightly lower than $10^{-6}$, extrapolated to the year 1990 .

Here, the criteria state that primary containment must maintain integrity and that reactor shutdown and decay heat rejection must be safely achieved.

\section{$3.3 \quad$ SNR-300}

\subsubsection{Design Basis Accidents and Requirements}

The design basis accidents for SNR-300 consisted (at least initially) of a broad range of internal events all of which can be categorized as either undercooling, overheating, local faults (in-core), and sodium fires. In addition, a set of external events had to be considered. The plant protection system was then designed to accommodate all these events. The core disruptive accidents were initially considered by the German licensing authorities to be hypothetical in terms of their likelihood of occurrence. Current 1icensing opinion has mandated that the plant be designed to protect against a prescribed mechanical energy release of $370 \mathrm{MW}-\mathrm{sec}$. 
The design basis accidents against external events can best be described by categorizing the external events themselves:

(a) Earthquake

(b) Aircraft Crash

- The design requirements for the design earthquake are that horizontal and vertical accelerations of $50 \mathrm{~cm} / \mathrm{s}^{2}$ (i.e., $0.05 \mathrm{~g}$ ) and $25 \mathrm{~cm} / \mathrm{s}^{2}$ (i.e., $0.025 \mathrm{~g}$ ), respectively, be tolerated as an upset condition. For the safety earthquake, acçelerations of $120 \mathrm{~cm} / \mathrm{s}^{2}(0.12$ g) and $60 \mathrm{~cm} / \mathrm{s}^{2}(0.06 \mathrm{~g})$ should be accommodated as an emergency condition.

- The design case for an aircraft crash accident is defined as the impact of a phantom plane with 0.65 Mach vertical to the building. The model of the loading process considers the elasticplastic deformation of the aircraft and results in a maximum force of $7.6 \times 10^{-2} \mathrm{MN}$ on the building.

(c) External Explosion - An external explosion is anticipated as a consequence of a ship collision on the Rhine river. The peak pressures in the reflection wave and the final static load were prescribed.

All these loadings (except for the design earthquake) must be individually applied to all systems necessary to keep the reactor in a shutdown condition. The decay heat must be dissipated and the radioactivity must be contained. Corresponding to the single failure criterion, a further failure (additional to the external event) must be assumed if such an additional failure has a not too remote probability of occurring.

The Plant Protection System of the SNR-300 is designed per KTA-rule 3501 to the following essential requirements:

1. Analysis of the course of the transients without taking into account PPS action.

2. The initial plant condition is defined as the most unfavorable normal operating condition, where set point deviations and a disturbance due to one random failure, for instance within the control system, are to be included.

3. For each accident to be guarded by the PPS, preferably physically diverse means of sensing have to be used. If this is not possible, a higher degree of redundancy and diversity within the various equipment has to be achieved.

4. If process variables common to the control system and the PPS have to be used (e.g., core outlet temperature), a detailed failure analysis in the area of data acquisition has to be performed. If channels of the PPS also serve control functions (e.g., permanent magnet flowmeter) its harmlessness also has to be demonstrated. 
5. Disturbances initiating faults within the PPS must not impair safety actions when called upon. The transient analyses have to begin with the assumption of a random fault, a systematic fault, and failures which might have been caused by those faults or by the considered transient. The criterion must also be fulfilled even if the system is in a condition of maintenance or repair (exception: a random fault and a systematic fault must not be assumed simultaneously within a time interval of 100 hours). The probability of a systematic fault can possibly be reduced by adequate means, so that its assumption is no longer necessary.

6. Manual actions are acceptable only if there is more than a 1/2-hour time period available in the case of internal events, and 10 hours in the case of external events.

7. The design of the plant protection system must not dictate the unavailability of the safety system.

The general idea to fulfill the requirements against either internal or external events is to provide (1) a diverse and independent shutdown system (as noted above) and (2) two redundant decay heat removal systems which are, together with all auxiliary systems necessary to operate them, completely independent from each other with the exception of those systems as the emergency power supply (which is housed in a building fully protected against external events).

The first redundancy is represented by the normal decay heat removal system. It comprises the main sodium loops, the steam generators, the water-steam systems for decay heat removal, the Rhine water cooling system, and the control room. Any one of the three sets of loops should be capable of dissipating decay heat. In the case of external events mentioned above, the first redundancy is assumed to be lost. The second redundancy is represented by the emergency cooling system. It comprises the in-vessel immersed cooler and associated circuits, emergency power, water supply, and emergency control functions. This path of heat removal consists of two circuits, either of which should be fully capable of discharging decay heat. This second level of redundancy is fully protected against external events mentioned earlier, at least those which can damage the first redundancy. Both systems are protected against internal events such as fires in accordance with the single failure criterion.

The fundamental internal event is the guillotine rupture of a pipe. It has to be assumed to occur primarily somewhere in the high pressure pipes of the water steam system. But it has also to be applied to sodium pipes, if the dissipation of the decay heat is concerned. Dynamic forces transferred by the breaking pipes to adjacent structures, sodium or hydrogen fires, and expansion of high pressure steam or water in the room in which the pipe fails are the relevant conditions to be considered as the consequences of such a primary internal event. 


\subsubsection{Transient Analysis}

The safety assessment of the SNR-300 plant was made in accordance with the KTA rule 3501 mentioned earlier. The following parameters are analyzed:

(a) Error in the measurement signal and the scram set point

(b) Failure of scram initiation signals

(c) Shutdown with a reduced number of rods

(d) Excessive delay during the rod insertion phase

(e) Superposition of such failures.

In each case it is of interest to determine the degree of failure that is tolerable without impairing the integrity of the core.

Example of events analyzed are:

(a) Normal Scram

There are among others, the following set points at which PPS initiates scram:

Function

Neutron flux

Ratio-flux to loop flow

Ratio-flux to core flow

Core outlet temperature

Temperature change $\Delta T$

$$
|\Delta T|
$$

Flux change

Normal operation at $100 \%$ load results in the flux to loop flow ratio of 1 and $T_{0}$ is the core outlet temperature at normal load. At $30 \%$ load, the normal value for the flux to loop flow ratio is 1 but the normal core outlet temperature is $40 \mathrm{~K}$ below that for the $100 \%$ load condition.

Scram can be initiated by the first PPS or the second PPS. The neutron flux decrease is prompt while the coolant flow reduces with a half-time of three seconds. Shutdown is assured with all 12 rods, but the activation of one or two rods would be enough 
to fulfill the essential safety requirements. The sensitivities due to delay in activating insertion of control rods and the insertion time are also analyzed. A delay of up to 5 seconds in activating and 15 seconds in insertion time is tolerable.

\section{(b) Loss of Power to all Pumps}

The worst anticipated flow reduction is due to a simultaneous coastdown of all pumps as in the case of a complete loss of electric power. Each PPS contains three scram signals which are sufficiently sensitive to scram the reactor in time. The first PPS is the flux to flow ratio (which causes scram at $1.5 \mathrm{~s}$ ), the seccond PPS is the core outlet temperature (scram at $3.6 \mathrm{~s}$ ), and the third PPS is the temperature change of $40 \mathrm{~K}$ (scram at 4.0 s). These scram times may be compared wi th 5.6-s delay required to boil sodium. Similar results for flow coastdown at $30 \%$ load are obtained.

\section{(c) Pump Seizure}

The spontaneous pump seizure of one primary pump produces smoother transients than loss of power to all pumps. Failure of one primary pump without scram would reduce the core flow to about $55 \%$ in the most unfavorable case. Even in this case, boiling would not occur.

(d) Withdrawal of Control Rods

Withdrawal of a control road and eight shim rods will result in a maximum reactivity insertion of $4 k / \mathrm{sec}$. Four different signals from the first PPS are able to limit the transient without fuel melting. The first scram is due to exceeding (in 3.0 seconds) the setting of flux to loop flow function. The second scram function is the flux to core flow ratio which is exceeded in $4.9 \mathrm{~s}$. The core outlet temperature setting is reached in $9.8 \mathrm{~s}$ and the temperature change signal is reached at $11.5 \mathrm{~s}$. Higher reactivity insertions are less demanding since the plant is scrammed earlier.

\section{(e) Guillotine Pipe Rupture}

The guillotine pipe rupture in the high pressure water/steam pipe initiates reactor scram, and the decay heat is dissipated through other loop/steam generators. The guillotine pipe rupture of the primary sodium piping is al so considered as a design basis accident. For all rupture locations independent of initial power level, the flux-to-core flow function of the second PPS becomes effective immediately after the accident and trips the reactor and pumps within 0.6 to $2.6 \mathrm{~s}$ depending on the initial power level. The second signal would be the sodium 
level in the reactor tank for which, because of the relatively late nuclear tripping, sodium boiling in "hot" channel would have to be expected. In addition to the reactor and pump trip, no further active measures are necessary to control the pipe rupture accident in respect of effective core cooling. The cavity concept ensures a leakage limitation in time and in volume and thereby a long-term decay heat removal via the two remaining operable main circuits. It is further noted that even for this situation, the in-vessel emergency core cooling is still available as a backup system.

\subsection{MONJU}

\subsubsection{Safety Design Criteria}

The safety design philosophy of MONJU is similar to that of CRBR. It is implemented by (a) setting up safety standards which provide the design basis, (b) completion of safety design, (c) design approval by safety evaluation, (d) quality assurance in component manufacturing, plant construction and postconstruction, (e) in-service inspection, and (f) safety demonstration. Since MONJU, like CRBR, is the first prototype LMFBR, essential design criteria are not available. The development of basic criteria is one of the objectives in the MONJU project.

For the purpose of accident analyses, all accidents are classified on the basis of their frequency of occurrence as follows:

Category A: Single-failure events which can occur several times during the life of plant.

Category B: The probability of occurrence of failure of a single component may be small, but such an event is expected to occur once during the life of plant.

Category C: Probability of occurrence is very small during plant's 1 ife, and it is considered to be unlikely, but such an occurrence is postulated for the safety design criteria.

Category D: An event which has the probability of occurrence smaller than that of Category $C$, or which is a combination of Category $A$ plus postulation of scram failure.

This classification of events is very similar to the CRBR approach in that Classes 1 through 3 are equivalent to Categories $A$ through $C$, and the Category $D$ appears to be similar to beyond the design basis events. The expected consequences for these categories are noted in Table IX.

The safety design criteria thus evolved for MONJU are listed below by components. 
Table IX. Classification of accidents used in MONJU

\begin{tabular}{|c|c|c|}
\hline $\begin{array}{c}\text { Category of } \\
\text { Events }\end{array}$ & $\begin{array}{c}\text { Expected Frequency } \\
\text { of Occurrence } \\
\end{array}$ & Consequences \\
\hline $\begin{array}{l}\text { A } \\
\text { (Minor Accidents) }\end{array}$ & $\begin{array}{l}\text { S Single Failure } \\
\text { o Expected to occur several times during } \\
\text { plant life } \\
\text { o Causes are anticipated }\end{array}$ & $\begin{array}{l}\text { Continuous smooth operation possible } \\
\text { o Fuel does not melt } \\
\text { o cladding does not fail }\end{array}$ \\
\hline (Medium Accidents) & $\begin{array}{l}\text { Single Failure } \\
0 \text { Expected to occur once during plant's life } \\
\text { o Causes are anticipated }\end{array}$ & $\begin{array}{l}\text { - Replaceable system components not so } \\
\text { damaged as to decrease their life time } \\
\text { o In the case of the system component that } \\
\text { can be maintained, it is possible to re- } \\
\text { pair it during refueling } \\
\text { o In the case of the system component that } \\
\text { cannot be replaced or maintained, a } \\
\text { damage that decreases its life time is } \\
\text { unacceptable } \\
\text { Fuel melting in minor region } \\
0 \text { Cladding strength decreases }\end{array}$ \\
\hline (Major Accidents) & $\begin{array}{l}\text { - Accidents are postulated to happen in the } \\
\text { worst case }\end{array}$ & $\begin{array}{l}\text { Repair will be required } \\
\text { operational trouble repairable within a } \\
\text { few months } \\
\text { o Fuel melt in small region } \\
\text { o Cladding failure possible - fission } \\
\text { product gas may be released to the } \\
\text { primary coolant }\end{array}$ \\
\hline
\end{tabular}


Table IX. Classification of accidents used in MONJU (Cont.)

\begin{tabular}{|c|c|c|}
\hline $\begin{array}{c}\text { Category of } \\
\text { Events }\end{array}$ & $\begin{array}{c}\text { Expected Frequency } \\
\text { of Occurrence }\end{array}$ & Consequences \\
\hline $\begin{array}{c}\text { D } \\
\text { (Hypothetical } \\
\text { Accident) }\end{array}$ & o Accidents postulated hypothetically & $\begin{array}{l}\text { - It is impossible to replace, repair, and } \\
\text { reoperate the damage system components } \\
\text { o Fuel and core materials are melted } \\
\text { o Core geometry has been damaged } \\
\text { o Core disruptive accident occurs } \\
\text { o Containment integrity is maintained, the } \\
\text { system components needed for maintaining } \\
\text { containment integrity are not damaged, } \\
\text { and their functions are retained } \\
\text { - System integrity needed for the decay } \\
\text { heat removal after core disruption is } \\
\text { maintained and required functions are } \\
\text { provided }\end{array}$ \\
\hline
\end{tabular}




\section{Reactor Core Design}

a. Reactor core, blanket, and associated cooling systems shall be designed such that the prompt power coefficient and the overall power coefficient in the power operating range should not be positive through the reactor life.

b. Reactor core, blanket, associated cooling systems, and control and protection systems should be designed not to exceed the fuel damage limits mentioned in the classification of accidents.

c. Assembly bowing shall be constrained by core clamping mechanisms which can accommodate fuel handling, scram characteristics, and core (nuclear, thermal) characteristics.

d. Core deformation by thermal, mechanical, and hydrodynamic forces under the normal operating and anticipated accident conditions shall be limited so as to prevent reactivity changes which may produce safety problems due to core deformation. Core deformation by earthquakes or other forces shall be limited so as to prevent positive reactivity insertion.

e. Fuel element vibration etc. by coolant flow does not cause nuclear and mechanical impropriety in the core.

f. Coolant flow rate in core shall be determined by considering material corrosion, etc. Pressure drop in the core shall be decided by considering the prevention of cavitation and the insurance of natural covection.

Fuel Design

a. Fuel element shall be designed to prevent fuel failure by fission product gas pressure, thermal expansion of fuel pellets and cladding, and swelling deformation, etc.

b. Maximum fuel temperature on overpower conditions should not exceed the fuel melting temperature during reactor operation.

c. Fuel element shall be designed so that an accident which exceeds the fuel damage limits does not occur by reactivity changes even if the axial fuel movement happens in the clad.

d. Reactor core shall be designed to minimize the probability of local blockages in a fuel assembly by impurities, debris, and foreign materials in sodium.

e. Fuel element must be designed so that mechanical, hydrodynamic and thermal effects by local failure do not impose any bad effects for adjacent assemblies, the extent of which are specified in the classification of accidents. Insertion of safety rods shall be ensured under the local accident. 
f. Proper measures must be taken to prevent core damage by fuel-handling errors if the core is composed of different kinds of fuel assembly. Mechanical means shal 1 be provided for protecting the insertion of core fuel into blanket region and vice versa.

\section{Control and Safety Rod Design}

a. Mechanical integrity and operational capability of both control and safety rods shall be ensured if any anticipated accident happens.

b. Safety rods shall be divided into two independent shutdown systems, with drive mechanisms operating on different principles from each other.

c. One of the shutdown systems has a margin of $1 \% \Delta \mathrm{k} / \mathrm{k}$ under the condition of one stuck rod. When one system cannot act, shutdown shall be ensured by other shutdown system and the shutdown condition shall be maintained under the cold critical.

d. Maximum reactivity worth of a control rod together with its withdrawal speed shall be limited to the extent such that the fuel damage limits mentioned in the classification of accidents is not exceeded.

e. Safety rods shall be inserted into the reactor core within one second after the scram signal reaches the drive mechanism.

f. Control rods, safety rods, and their drive mechanisms shall be designed to prevent movement in the directions which add the reactivity.

Reactor Vessel Design

a. Reactor vessel shall be designed, constructed, installed, and tested according to the highest-quality criteria that are practical.

b. Under stress due to normal operation, maintenance, testing, and accident conditions for the reactor vessel integrity shall be evaluated with sufficient margins with respect to (a) embrittlement characteristic behavior, (b) radiation effects on material characteristics, and (c) size of defect.

c. Reactor vessel shall be designed with consideration to thermal shock due to reactor scram.

d. For reducing radiation damage of reactor vessel, it is necessary to install neutron shielding.

e. Reactor vessel shall be designed to ensure the integrity of vessel in the event of a hypothetical core-disruptive accident. 
f. To prevent oxides from depositing in the region where sodium flow is stagnant, it is necessary to ensure the sodium flow even in such small areas as gaps between assemblies.

g. Vent holes shall be provided for removing gas from the reactor vessel, inlet plenum, and internals. However, core internals shall be designed to limit entry into the core of large quantities of gas bubbles.

h. Core internals including shielding materials shall be designed to be removed when refueling or maintenance is required.

i. The entrance nozzle is designed to have a large reverse flow resistance for ensuring the core integrity in the event of pipe failure near the entrance nozzle.

j. Drain system shall be installed to check or maintain the core internals. However, sodium must not be drained as the result of operator error, control malfunction, and/or drain piping failure.

k. Reactor vessel shall be designed for easy periodic testing or inspections required by in-service inspection $\mathrm{plan}$ which is necessary for evaluating the structural integrity of important parts.

\section{Shield Plug Design}

a. Shield plug shall be designed to protect operating personnel from radiation during normal maintenance and fuel handling.

b. Cover gas leakage shall be severely limited to prevent the leakage of radioactive materials, to maintain cover gas pressure during normal operation, and to prevent impurities entrance into coolant.

c. Measures shall be taken to prevent sodium leakage through the gaps between shield plug and reactor vessel or equipment plugs on shield plug caused by pressure buildup in the reactor vessel due to the hypothetical core disruptive accident.

d. Proper measures shall be taken for preventing the shield plug and equipment on it from ejecting like missiles because of pressure buildup in the reactor vessel during a hypothetical core-disruptive accident.

Guard Vessel Design

a. Guard vessel shall be of simple structure, for example, fewer nozzles and of symmetrical configuration, and shall be designed of independent structure to prevent the direct external loads from other components.

b. Guard vessel shall contain and hold the leaked sodium safely under any circumstances. 
c. Guard vessel shall be designed with space for installing leak detectors capable of detecting sodium leakage from reactor vessel or primary piping.

d. Space between reactor vessel and guard vessel and height of guard vessels shall be determined by considering the sodium level in the reactor vessel required for the decay heat removal after the primary pipe failure accident.

e. Gaps between components and their guard vessels shall be large enough size to satisfy the in-service inspection requirement.

\section{Main Cooling Systems Device}

a. Main coolant piping shall be of single wall.

b. Suitable design must be provided not to exceed the fuel failure limits. For example, the reverse flow resistance of the inlet nozzles and the flow resistance between the reactor and the guard vessels should be enhanced as much as possible.

c. The design of the primary and secondary loops shall provide the sufficient capability of decay heat removal both by natural circulation and by the inertia of pumps.

d. The primary loops shall be designed to ensure, in the event of a small pipe failure, a positive pressure at normal operation to prevent entrance of small gas bubbles into the coolant systems.

e. The main coolant system shall be designed to maintain its integrity against thermal shocks and cyclings of the frequency and amplitude anticipated during the plant life.

f. To prevent the sodium level in the reactor vessel from falling below the emergency level in the event of the primary loop piping failure, all the primary loop piping is contained within the guard vessel or is elevated to a horizontal level above the top of the guard vessels.

g. Check valves shall be installed in the primary loops and shall be reliable and maintainable.

h. Supply of the cover gas shall be terminated if the main primary piping fails so as to minimize the core flow decrease. Proper measures must be taken, however, not to make the pressure decrease excessive.

i. Sodium purity shall be controlled to minimize the effects of sodium impurities on the materials and the occurrence of local blockages in the core.

\section{Emergency Core Cooling System Design}

a. The emergency core cooling system shall be installed to maintain a reactor flow in the event of a component failure and the breach of the coolant boundary. 
b. The emergency core cooling system shall be designed to provide the reactor flow for ensuring the core integrity both by forced circulation and by natural convection.

c. The emergency core cooling system shall be designed to perform its safety function even if the following conditions are assumed: (1) a single failure of any active component after a short time, and (2) a single failure of any active or passive component a long time after accident.

\section{Protection Systems and Engineered Safety Features Design}

Protection systems and engineered safety features must be designed to satisfy the following requi rements:

a. Fail-safe design.

b. Foolproof design.

c. Design as passive as possible.

d. Redundant and diverse design.

e. Design which al lows maintenance and inspection during reactor operation.

f. Seismic design of Class As or A.

g. Designs independent of one another; for example, the failure of one system will not cause damage to another.

\section{Containment Design}

a. The containment shall be of a double-containment structure consisting of primary and secondary containments.

b. The leakage rate from the containment system including access openings, penetrations, etc. shall be designed not to exceed the design value with a sufficient margin. Under the hypothetical accidents, the containment system shall not fail because of missiles of equipment and it shall contain the released fission products or plutonium. The containment system shall withstand the pressure and temperature of the maximum postulated sodium leakage, and it shall be designed to minimize the radiation dose to the public within the limit in the "guide for investigation of reactor site condition."

c. The reactor building and contaimment shall be designed to withstand with a sufficient margin natural disasters such as earthquakes, tornadoes, floods, tsunamis (tidal waves), and wind.

d. The oxygen content in nitrogen atmosphere within the primary equipment cells and the access cover pit shall be controlled at a low level so as to diminish the possibility of sodium fire. 
e. A floor area that might be immersed in leaked sodium shall be partitioned so as to limit the size of a sodium pool fire.

f. Within the containment, use of water shall be prohibited and the use of lubrication oils of carbon-hydride and of freon shall be minimized.

Fuel-Handling Systems Design

a. Fuel storage facility for fresh and irradiated fuel elements shall be designed geometrically against criticality under normal fuel handling.

b. Cladding temperature of irradiated fuel (including elements removed) shall be designed not to exceed the allowable maximum temperature at normal operation.

c. An appropriate cleanup system and shielding shall be provided to protect the operating personnel from radioactivity.

d. Every component of the fuel handling system shall be designed to protect fuel elements against mechanical failure under normal fuel handling.

Seismic Design Basis

For the purpose of seismic design, all buildings, structures, pipings, and components and their appurtenances are separated into the following four seismic classes according to the importance of their functions in reactor safety:

Class As: Especially important installations for reactor safety, such as reactor containment and the reactor shutdown devices.

Class A: Installations necessary to protect the public from radiation hazards in the event of nuclear incidents and whose functional failure would lead to an occurrence of nuclear accident.

Class $B$ : Installations related to highly radioactive materials except those in the Classes As and A.

Class C: Installations not included in the Classes As, A, and B.

The design principles are:

(a) All installations in the Classes As and A must maintain their functions, even if adjacent systems in the lower classes fail.

(b) Components and pipings in the Classes As and $A$, as a rule, must be supported by buildings and structures of Class $A$ or $B$. In case of supporting components and pipings of $C l$ ass $A$ by buildings and structures of Class $B$, these supporters must be examined dynamically as Class A. 
(c) Important high temperature pipings must be designed in the rigid region without excessive restraint of thermal deformation and to avoid the resonance vibration. Moreover, a supporting system with proper supporting arrangement must be selected to protect against the external deformation force by their supporting mechanisms or supporting structures.

(d) The station power system, measurement and control systems, and their supporting mechanisms must be designed in the rigid region in accordance with the analytical method of each class in the event of design basis earthquake.

\subsubsection{Design Basis Accidents}

The design basis accidents considered in MONJU are divided in two parts: abnormal transients and accidents. The abnormal transients are events in which external disturbances exceeding normal operation of the plant are expected to occur because of simple mechanical failure, erroneous actuation, or operator errors as well as those events which are unexpected but which nevertheless may still occur. The accidents are abnormal events whose consequences may exceed those studied under abnormal transients, and though they have only a slight possibility of occurrence yet they must be considered in the safety analysis. These two categories of events together appear to comprise DBA events. While most of the abnormal transients considered in MONJU may be given the anticipated' grade in our terminology, some of these events could be under the 'unlikely' grade. Similarly, the accident events may be analogous to the 'unlikely' and 'extremely unlikely' events.

The acceptance criteria for the abnormal transients may be summarized as the following: the core must be maintained in a state in which reversion to usual operation of the plant is possible without any reduction in plant life. The standards for judging this are as follows:

(i) The temperature at the center of the cladding tube must be below $830 \mathrm{C}(1526 \mathrm{~F})$ so that the fuel cladding tube does not burst as the result of internal pressure of plenum gas.

(ii) The core sodium temperature must be below $920 \mathrm{C}(1668 \mathrm{~F})$ to ensure that the coolant does not boil.

(iii) The fuel temperature must be below its melting point to ensure that the fuel cladding tube does not burst due to fuel melting.

(iv) The temperature of the reactor coolant boundaries must not exceed either $600 \mathrm{C}(1112 \mathrm{~F}$ ) or 1.4 times the maximum temperature used (in C) whichever is lower.

The acceptance criteria for accidents may be summarized as the following: the vicinity of the site must not be greatly affected by the radiation and the danger of core melting must be prevented. The standards for judging this are as follows: 
(i) The core should not suffer major damage and sufficient cooling should be possible.

(ii) The temperature of the reactor coolant boundaries must not exceed either $650 \mathrm{C}(1202 \mathrm{~F}$ ) or 1.6 times the maximum temperature used (in C) whichever is lower.

(iii) The pressure imposed on the reactor containment boundary should be bel ow the maximum pressure used.

(iv) There should be no risk of extreme radiation exposure to the surrounding populace.

All abnormal transients are grouped as:

(a) Transients which induce abnormalities in reactivity and power

(1) Abnormal withdrawal of control rods from the subcritical state

(2) Abnormal withdrawal of control rods during power operation

(3) Control rod drop

(b) Transients which induce abnormalities in the primary coolant flow rate

(4) Reduction in the primary coolant flow rate

(5) Increase in the primary coolant flow rate

(6) Loss of external power

(c) Transients which cause abnormalities in the primary coolant temperature

(7) Reduction in the secondary coolant flow rate

(8) Increase in the secondary coolant flow rate

(9) Reduction in feedwater flow rate

(10) Increase in the feedwater flow rate

(11) Loss of load

(12) Small leak in steam generator

All of these abnormal conditions are analyzed and the predicted maximum fuel and cladding temperatures are noted in Table $X$. Some details of these analytical assumptions are also given in this table. The reactor is assumed to 
Table $X$. List of abnormal events considered and the results of analysis for MONJU plant

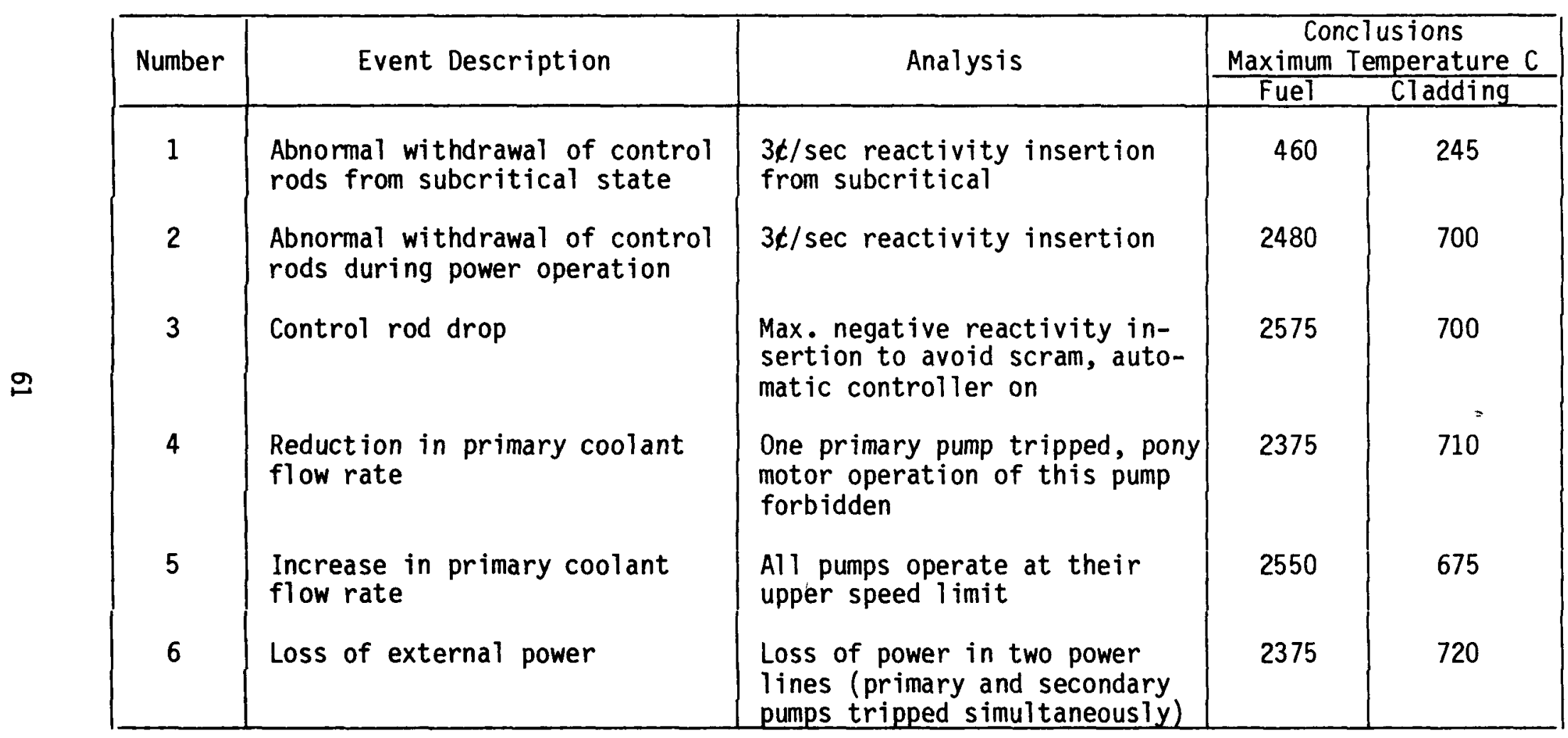


Table $x$. List of abnormal events considered and the results of analysis for MONJU plant (Cont.)

\begin{tabular}{|c|c|c|c|c|}
\hline Number & Event Description & Analysis & \multicolumn{2}{|c|}{$\begin{array}{c}\text { Conclusions } \\
\text { Maximum Temperature } c\end{array}$} \\
\hline 7 & $\begin{array}{l}\text { Reduction in secondary coolant } \\
\text { flow rate }\end{array}$ & One secondary pump is tripped & 2375 & 680 \\
\hline 8 & $\begin{array}{l}\text { Increase in secondary coolant } \\
\text { flow rate }\end{array}$ & $\begin{array}{l}\text { All secondary pumps operate at } \\
\text { their upper speed limit }\end{array}$ & 2525 & 688 \\
\hline 9 & $\begin{array}{l}\text { Reduction in feedwater flow } \\
\text { rate }\end{array}$ & $\begin{array}{l}\text { Two main feedwater pumps are } \\
\text { tripped simultaneously }\end{array}$ & 2375 & 680 \\
\hline 10 & $\begin{array}{l}\text { Increase in feedwater flow } \\
\text { rate }\end{array}$ & $\begin{array}{l}\text { Feedwater adjustments of three } \\
\text { loops are opened simultane- } \\
\text { ously }\end{array}$ & 2525 & 685 \\
\hline 11 & Loss of load & $\begin{array}{l}\text { Complete loss of load, main } \\
\text { feedwater pump tripped }\end{array}$ & 2375 & 680 \\
\hline 12 & Small leak in steam generator & $\begin{array}{l}\text { Range of water leakage from } \\
0.00 \text { to } 0.1 \mathrm{gal} / \mathrm{sec}\end{array}$ & 2375 & \\
\hline
\end{tabular}


be operating at its rated power of $714 \mathrm{MWt}$. The reactor trip signal is issued when the process quantity monitored by the Plant Protection System exceeds the set level.

The MONJU plant is also analyzed for a range of "accident" conditions. These are grouped as follows:

(a) Accidents resulting in reactivity

(1) Rapid withdrawal of control rod at the maximum permissible rate

(2) Fuel slumping accident

(3) Bubble passage through the core

(b) Accidents resulting in reduction in cooling capability

(4) Coolant channel blockage

(5) Primary pump seizure

(6) Secondary pump seizure

(7) Main feedwater pump seizure

(8) Primary coolant leakage

(9) Secondary coolant leakage

(10) Main steam pipe rupture

(11) Main feedwater pipe rupture

(12) Pipe rupture in a steam generator

(c) Accidents resulting in discharge of other radioactivity matter

(13) Primary sodium auxiliary facilities leakage

(14) Primary argon gas leakage

(15) Fuel replacement handling accident

(16) Gaseous waste treatment system rupture accident.

These accidents are analyzed and the predicted responses are noted in Table $X I$. In addition to the above-mentioned abnormal transients and accidents, the MONJU plant also considers two major accidents and a hypothetical accident. The two major accidents are:

(1) Primary argon gas leakage accident,

(2) Primary coolant leakage accident. 
Table XI. List of accident events considered and the results of analysis for MONJU plant

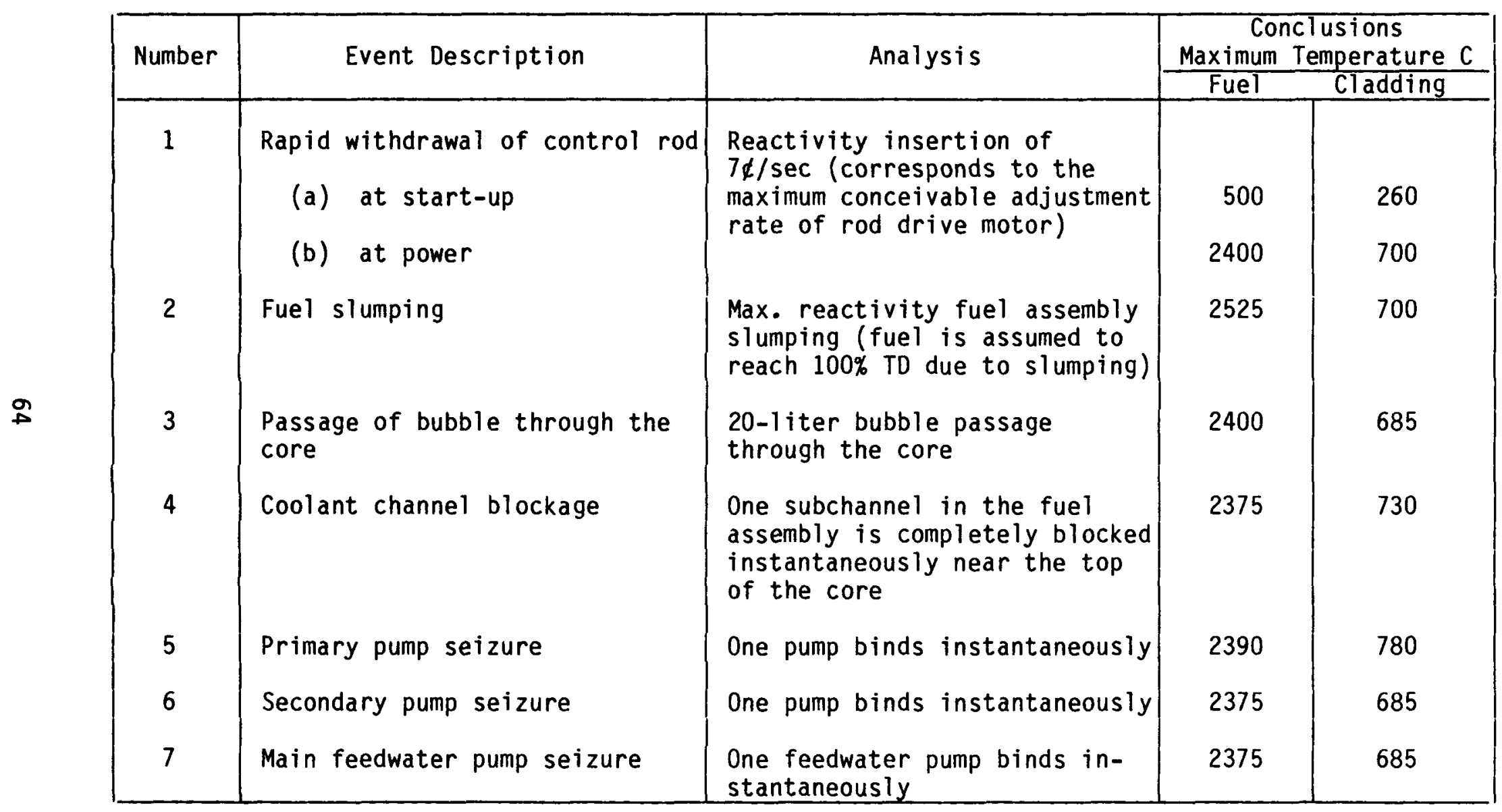


Table XI. List of accident events considered and the results of analysis for MONJU plant (Cont.)

\begin{tabular}{|c|c|c|c|}
\hline Number & Event Description & Analysis & $\begin{array}{c}\text { Conclusions } \\
\text { Maximum Temperature C }\end{array}$ \\
\hline & & & Fuel Cladding \\
\hline 8 & Primary coolant leakage & $\begin{array}{l}2 \mathrm{~cm}^{2} \text { rupture at the inlet } \\
\text { nozzle of the reactor vessel; } \\
\text { power is also lost simultane- } \\
\text { ously }\end{array}$ & $\begin{array}{l}2375 \\
\text { Na discharge rate of } 79 \\
\mathrm{~kg} / \mathrm{sec} \text { (normal } \mathrm{Na} \text { flow } \\
\text { rate } 4270 \mathrm{~kg} / \mathrm{sec} \text { ). SQ- } \\
\text { dium leakage of } 250 \mathrm{~m}^{3} \\
\text { (63,000 gallons) in RV, } \\
240 \mathrm{~m}^{3} \text { ( } 63,400 \mathrm{gal}- \\
\text { lons in the primary } \\
\text { coolant chamber. The } \\
\text { maximum containment } \\
\text { pressure rjse of } \\
0.008 \mathrm{~kg} / \mathrm{cm}^{2}(0.11 \mathrm{psi}) .\end{array}$ \\
\hline 9 & $x^{2}$ & $\begin{array}{l}\text { Rupture of the secondary } \\
\text { piping between the IHX and the } \\
\text { pump - no heat removal from } \\
\text { this IHX }\end{array}$ & \begin{tabular}{l|c}
\multicolumn{1}{c|}{2375} & 680 \\
& \\
Fire-proof partitions \\
in each secondary \\
coolant piping as \\
well as fire detection \\
equipment control \\
spread of sodium fire
\end{tabular} \\
\hline 10 & Main steam pipe rupture & $\begin{array}{l}\text { Rupture of pipe between tur- } \\
\text { bine and steam generator }\end{array}$ & 2375 \\
\hline 11 & Main feedwater pipe rupture & $\begin{array}{l}\text { Rupture of pipe between the } \\
\text { steam generator and the main } \\
\text { feedwater }\end{array}$ & 2375 \\
\hline
\end{tabular}


Table XI. List of accident events considered and the results of analysis for MONJU plant (Cont.)

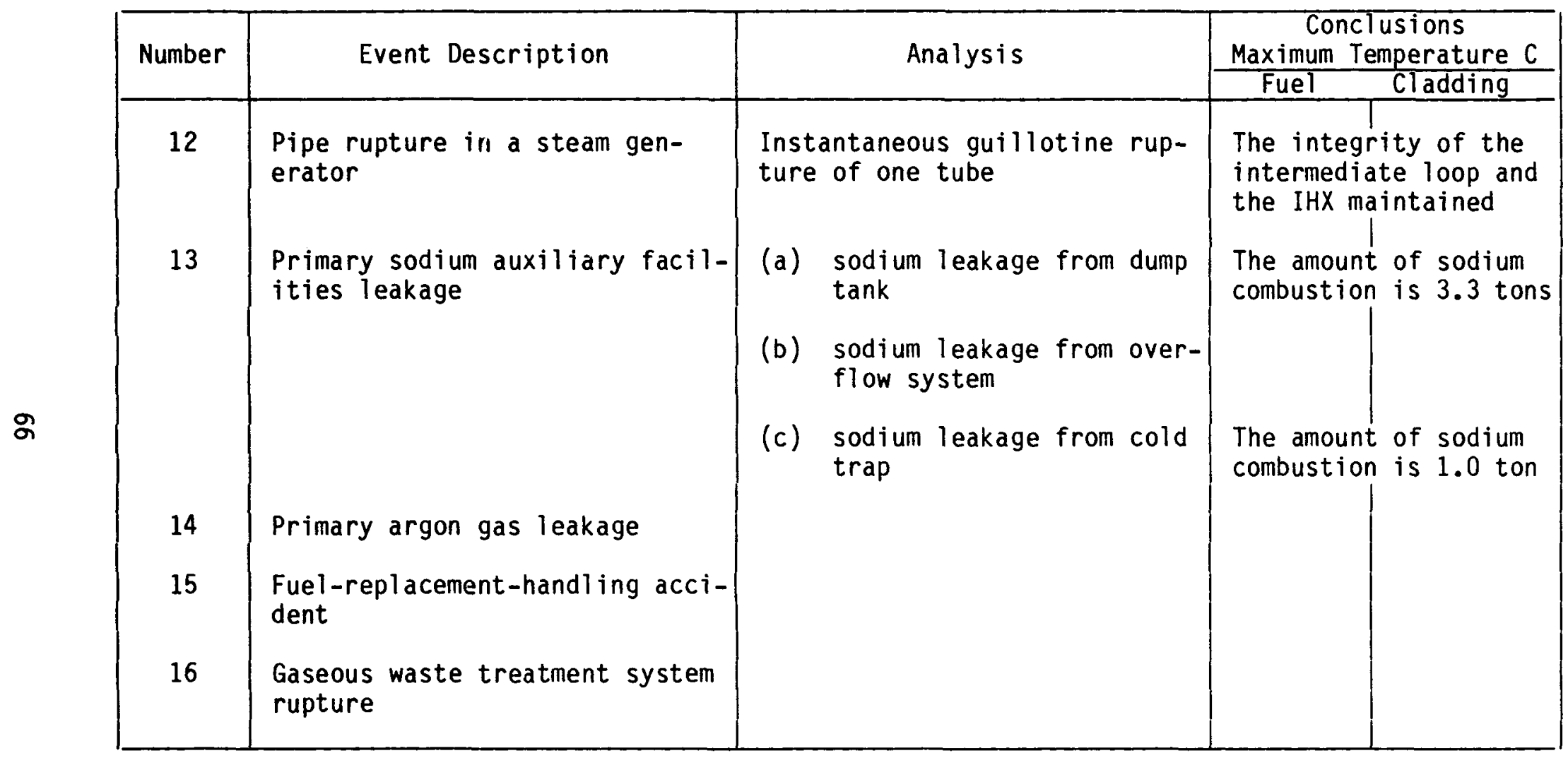


The primary argon gas leakage accident considered previously as an "accident" results in the release of iodine (I 131 equivalent) of approximately $1.1 \mathrm{Ci}$ and dilute gases (converted to $0.5-\mathrm{meV}$ gamma ray) of $2.4 \times 10^{4} \mathrm{Ci}$. The level of releases under 'major accident' are $2.5 \mathrm{Ci}$ and $7.8 \times 10^{4} \mathrm{Ci}$, respectively. Similarly, the amount of leakage of radioactivity considered under 'major accident' is considerably larger as compared with the 'accident' classification. The hypothetical accident envisioned was the primary coolant leakage accident just discussed (major accident) except that even larger amounts of radioactivity releases were used.

\subsection{General Comments}

1. The Design Basis Accidents are a set of credible incidents which may occur or are expected to occur in an LMFBR or a group of LMFBRs. All these events must be factored in the plant design. Accordingly, the entire system need not be designed for hypothetical events such as HCDAs. The Clinch River Breeder Reactor Plant has been thus designed by considering all identifiable events as DBAs. Additionally, the CRBR provides structural and thermal margins for events beyond the Design Basis Accidents (SMBDB and TMBDM). The accommodation for these beyond DBAs is reviewed by the NRC and its consultants elsewhere. This delineation between the design basis and beyond design basis events is somewhat harder to make in foreign plants.

2. There is considerable interest in following HCDA progression. In fact, most of the readily available literature on the foreign plants tend to be in this area.

3. In terms of the DBAs and their accommodation by the plant, the Plant Protection System plays a key role both in terms of the functions used and in the set points. For example, in SNR-300 DBA analyses, the first PPS function was always discredited. Even some delays in the actuation of the control rods and their insertion time were found to be acceptable.

4. In the case of FFTF, a potential problem had to do with the freezing of sodium. As the heat is dissipated directly to air, perhaps such an event plays an important role in the DBA set for FFTF. In SNR-300, there is a reactor scram function based on low feedwater temperature. This setting is used primarily to protect the steam generator and possibly to prevent sodium from freezing. The CRBR PSAR relies on control and surveillance.

5. The role of delayed neutron detection needs some further consideration. Once an acceptance level for the number of failed fuel pins is established, it may be helpful to provide a scram signal when DND activity exceeds a set value as opposed to providing just an alarm (as in the case in CRBR). The prime justification for this recommendation is to arrest potential assembly-to-assembly failure propagation. This type of event can proceed either by a sudden blockage of an assembly or by loading errors. The former was responsible for the partial meltdown of the FERMI reactor. This situation is largely 
designed-out in more contemporary plants such as FFTF, CRBR, PHENIX, and others. The SNR-300 has scram function based on the DND activity.

6. The SNR-300 plant has protective settings based on the high as well as the low cover gas pressures. The CRBR PSAR has control and surveillance functions based on the cover gas pressure.

7. All of the plants studied and discussed here provide for at least two independent and diverse shutdown systems.

8. The shutdown heat removal systems tend to vary somewhat from one plant to another. While the pool systems appear to provide greater flexibility and more time in handling decay heat, the loop systems are also quite sophisticated. The shutdown heat removal systems for CRBR, PHENIX, SNR-300, MONJU, and PFR are summarized in Table XII. 
Table XII. A comparison of shutdown heat removal systems

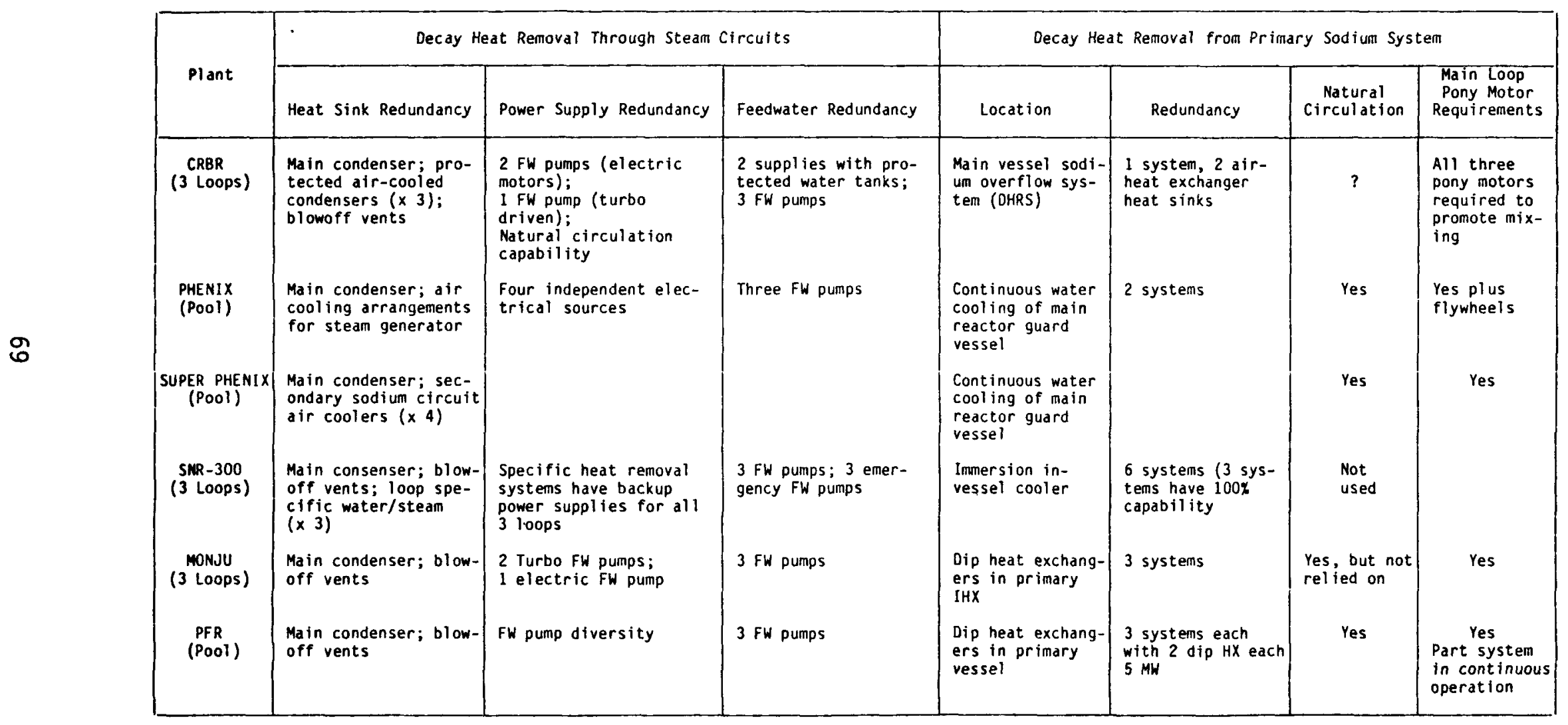




\section{ACKNOWLEDGMENTS}

This work was done under the auspices of the US Nuclear Regulatory Commission. The author would like to thank C. Allen for encouragement and R. A. Bari for technical and supervisory support. Informal discussions with G. Kessler (KfK) and H.J. Hubel (Interatom) were also very helpful. Thanks are al so expressed to $C$. Moore and $\mathrm{N}$. Nelson for typing this manuscript under very demanding conditions, and to M. Rustad for editorial assistance. 


\section{REFERENCES}

1. J.E. Hanson, "Comparison of Clinch River Breeder Reactor Design Basis ACcidents with those for Light Water Reactors and Liquid-Metal Cooled Fast Reactors", Idaho National Engineering Laboratory, EGG-NTAP-6152, January 1983.

2. "Standard Format and Content of Safety Analys is Reports for Nuclear Power Plants - LMFBR Edition", issued by US Nuclear Regulatory Commission, February 1974.

3. "Standard Format and Content of Safety Analysis Reports for (LWR) Nuclear Power Plants", issued by US Nuclear Regulatory Comission, October 1972.

4. J.G. Guppy et. al., "Technical Evaluation of the CRBR Heat Transport System Design", Draft Report, Brookhaven National Laboratory, April 1982.

5. L.F. Franzen, "The Nuclear Licensing and Supervisory Procedures for Nuclear Facilities in the Federal Republic of Germany", Gesellschaft fur Reaktorsicherheit (GRS) Report, GRS-43, February 1982.

6. M.W. Gol ay and M. Casti1lo, "Comparative Analysis of LMFBR Licensing in the United States and Other Countries - Notably France", Charles River Research Report CRR-001, UCRL-15425, September 1981.

7. "Risikoorientierte Analyse zum SNR-300 - Bericht der GRS", Gesell schaft fur Reaktorsicherheit (GRS) mbH, West Germany, Report No. GRS-A-700 Vol. 1 and 2, Aprit 1982.

In addition to the above references, a number of other papers were used to excerpt the information on the foreign plants. These publications are grouped by the plant concerned.

SNR-300

1. H.J. Hubel, "The Safety-related Criteria and Design Features for SNR", in Proc. of the Fast Reactor Safety Meeting, Beverly Hills, California, April 2-4, 1974, CONF-740401.

2. F.H. Morgenstern, H. Buchholz, H. Kruger and H. Rohrs, "Diverse Shutdown Systems for the KNK-1, KNK-2 and SNR-300 Reactors" in Proc. of the Fast Reactor Safety Meeting, Beverly Hills, California, April 2-4, 1974 , CONF-740401.

3. D. Smidt, "Selection of Safety Design Basis of Fast Reactors in the Federal Republic of Germany", in Proc. of the Fast Reactor Safety Meeting, Beverly Hills, California, April 2-4, 1974, CONF-740401, p. 1635 .

4. E. Kugler and S. Wiesner, "Licensing Aspects in the Verification of the SNR-300 Design Concept against Hypothet ical Accidents", in Proc. of the International Meeting on Fast Reactor Safety and Related Physics, Chicago, October 5-8, 1976, CONF-761001, Vol. I, p. 14. 
5. H. Oeynhausen, F. Morgenstern, U. Scholle, L. Lange, and G. Waldhor, "Design Requirements for the SNR-300 Containment System", in Proc. of the International Meeting on Fast Reactor Safety and Related Physics, Chicago, October 5-8, 1976, CONF-761001, Vo1. II, p. 452.

6. F.H. Morgenstern, W. Gyr, D. Stotzel, H. Vossebrecker, "The Decay Heat Removal Plan of the SNR-300 - A Licensed Concept", in Proc. of the International Meeting on Fast Reactor Safety and Related Physics, Chicago, October 5-8, 1976, CONF-761001, Vol. II, p. 442.

7. K. Traube, "Safety Design of SNR-300", in Proc. of the International Meeting on Fast Reactor Safety and Related Physics, Chicago, October 5-8, 1976, CONF-761001, Vol. I, p. 84.

8. G. Kessler, "Safety Levels Satisfactory for the Commercialization of the LMFBR", in Proc. of the International Meeting on Fast Reactor Safety Technology, Seattle, Washington, August 19-23, 1979, Vol. V, p. 2672.

9. W. Lindner, K. Mendle, and H. Reimann, "Experiments on the Reventing System of the SNR-300 as part of the Containment under Simulated Accident Conditions", in Proc. of the International Meeting on Fast Reactor Safety Technology, Seattle, Washington, August 19-23, 1979, Vol III, P. 1211.

10. F.H. Morgenstern, F. Brandl, V. Ertel and A. Schonsiegel, "The Plant Protection System of the SNR-300 - Requirements and Design", in Proc. of the Fast Reactor Safety Technology, Seattle, Washington, August 19-23, 1979, Vol. V, p. 2602.

11. H. Vossebrecker and A. Kellner, "Inherent Safety Characteristics of Loop-type LMFBRs", in Proc. of the International Meeting on Fast Reactor Safety Technology, Seattle, Washington, August 19-23, 1979, Vol. II, p. 554.

12. V. Ertel and F. Brand1, "Safety Margins in the Protection of the SNR -300 Core", in Proc. of the International Topical Meeting on Liquid Metal Fast Breeder Reactor Safety and Related Design and Operational Aspects, Lyon, France, July 19-23, 1982.

13. D. Struwe, P. Royl and R. Frohlich, "Vessel Failure Event Tree Analysis of SNR-300 for a Hypothetical Unprotected Loss-of-Flow Accident", in Proc. of the International Topical Meeting on Liquid Metal Fast Breeder Reactor Safety and Related Design and Operational Aspects, Lyon, France, July 19-23, 1982.

14. H. Zeibig, L. Gruter and M. Fortmann, "Safety Concept of SNR-300 and SNR-2 with respect to Sodium Leakages", in Proc. of the International Topical Meeting on Liquid Metal Fast Breeder Reactor Safety and Related Design and Operational Aspects, Lyon, France, July 19-23, 1982.

15. U. Daunert, R. Lamarche, and H.K. Mani, "The German-Bel gium-Dutch Fast Breeder Collaboration: Its Aim and Organization", Nucl. Eng. International, 21, p. 39, July 1976 . 
16. A. Brandstetter and A.W. Eitz, "The Tripartie Fast Breeder Programme: A Utility/Industry View", Nucl. eng. International 21, p. 40, July 1976.

17. J.M. Morelle, K.W. Stohr and J. Vogel, "The Kalkar Station, Design and Safety Aspects", Nucl. Eng. International, 21, p. 43, July 1976.

18. S. Dreyer, "The Heat Transfer System of SNR-300", Nucl. Eng. Internationa), 21, p. 49, July 1976.

19. A.H. de Haas van Dorsser, "Main Heat Transfer Components for SNR-300", Nucl. Eng. Internationa1, 21, p. 51, July 1976.

20. J.P. Van Dievoet, "The Fuel for SNR-300", Nucl. Eng. International, 21, p.54, July 1976 .

21. F. Vogt, "The SNR-300 Fuel Handling System", Nucl. Eng. International, 21, p. 56, July 1976 .

MONJU

1. K. Terata, T. Saito and Y. Nishikawa, "Selection of Safety Design Bases for MONJU", in Proc. of the Fast Reactor Safety Meeting, Beverly Hills, California, April 2-4, 1974, CONF-740401, p. 51.

2. S. An and Y. Togo, "Key Issues on Safety Design Basis Selection and Safety Assessment", in Proc. of the International Meeting on Fast Reactor Safety and Related Physics, Chicago, October 5-8, 1976, CONF-761001, p. 2.

3. K. Kawashima and Y. Suzuki, "Safety-Related Design of MONJU", in Proc. of the International Meeting on Fast Reactor Safety and Related Physics, Chicago, October 5-8, 1976, CONF-761001, p. 98.

\section{PHENIX}

1. R. Carle, J. Megy and J.C. Moreau, "Fast Neutron Power Reactor PHENIX", Nuc 1. Eng. International, 16, 557 (1971).

2. M. Labat, "Site Work for the PHENIX Plant", Nuc1. Eng. International, 16, 564 (1971).

3. J.L. Befre, J.P. Delisle and M.G. Robin, "Circuits and Main Components", Nucl. Eng. International, 16, 567 (1971).

4. E. Benoist and C. Boulinier, "Fuel and Special Handling Facilities for PHENIX", Nuc1. Eng. Internationa1, 16, 571 (1971).

5. M. Chapelot, "Instrumentation, Control and Monitoring Systems", Nucl. Eng. International, 16, 577 (1971). 
6. R. Carle, J. Megy and B. Guillemard, "PHENIX Startup", in Proc. of the Fast Reactor Safety Meeting, Beverly Hills, California, April 2-4, 1974, CONF-740401, p. 1009 .

7. J. Goddet, "Operating Experience with the PHENIX Nuclear Power Station from the Point of View of Safety", in Proc. of the International Meeting on Fast Reactor Safety and Related Physics, Chicago, October 5-8, 1976, CONF-761001, p. 76 .

\section{SUPER PHENIX}

1. J. Megy, J. Leduc, A. Chalot, A. Guidicelli, E. Robert, E. Rodet, J.P. Crette, and C. Malaval, "SUPER-PHENIX Preliminary Safety Analysis: General Related Criteria and Main Features", in Proc. of the Fast Reactor Safety Meeting, Beverly Hills, California, April 2-4, 1974, CONF-740401, p. 29 .

2. J.F. Petit, "Safety Design Basis for Power LMFBR", in Proc. of the Fast Reactor Safety Meeting, Beverly Hills, California, April 2-4, 1974 , CONF-740401, p. 1683.

3. P. Tanguy, J. Petit and F. Justin, "Key Safety Issues for Fast Breeder Reactors", in Proc. of the International Meeting on Fast Reactor Safety and Related Physics, Chicago, October 5-8, 1976, CONF-761001, p. 24.

4. E. Robert, G. Lucenet, A. Chal ot and J. Leduc, "Main Safety Features of the SUPER-PHENIX Project", in Proc. of the International Meeting on Fast Reactor Safety and Related Physics, Chicago, October 5-8, 1976, CONF-761001, p. 164 .

5. J.C. Lefevre, M. Livolant and G. Lucenet, "Seismic Analysis for the SUPER-PHENIX Reactor", in Proc. of the International Meeting on Fast Reactor Safety and Related Physics, Chicago, October 5-8, 1976, CONF-761001, p. 180.

6. J.F. Petit, "Summary on Licensing Considerations and Selection of safety Design Basis: Summary on Safety-Related Operation/Design Experience Pertaining to Demonstration and Large Fast Breeder Plants", in Proc. of the International Meeting on Fast Reactor Safety and Related Physics, Chicago, October 5-8, 1976, CONF-761001, p. 302 .

7. M. Banal, "Work Starts on SUPER-PHENIX at the Creys-Malville Site", Nucl. Eng. Internationa1, 22, 41 (1977).

$\underline{P F R}$

1. A.G. Frame, W.G. Hutchinson, J.M. Laithwaite and H.F. Parker, "Design of the Prototype Fast Reactor", Proc. London Conf. on Fast Breeder Reactors, May 17-19, 1966, pp. 291-315.

2. R.V. Moore, "The Dounreay Prototype Fast Reactor", Nucl. Eng. International, 16, 629 (1971). 
3. J.0. Grieves, "The Place of Fast Reactors in the U.K. Power Programme", Nucl. Eng. Internationa1, 16, 630 (1971).

4. K.J. Henry, "Technical Description of PFR", Nucl. Eng. International, 16, $632(1971)$.

5. J. Hannaford and D.R.H. Fryer, "Safety Issues in Licensing Commercial LMFBR's", in Proc. of the International Meeting on Fast Reactor Safety and Related Physics, Chicago, October 5-8, 1976, CONF-761001, p. 33. 


U.S. NUCLEAR REGULATORY CCMMISSION
BISRC FORM 335
$(7.7)$

4. TITLE ANO SUBTITLE (Ado Volume No., if eppropriate)

1. REPORT NUMBER (Assigned bY ODC)

NUREG/CR-3240

BNL/NUREG-51663

2. (Leave olonk)

3. RECIPIENT'S ACCESSION NO.

5. DATE REPORT COMPLETED \begin{tabular}{l|l}
\hline MTNTH & YEAF \\
\hline
\end{tabular} January 1983

Ashok K: Agrawal

3. FEMFORAIING ORGANIZATION NAME ANO MAILING ADORESS (Include Zip Code)

Department of Nuclear Energy

Brookhaven National Laboratory

Upton, New York 11973

12. SPONSORING ORGANIZATION NAME AND MAILING ADDRESS (Include Zip Code)

Clinch River Breeder Reactor Project Office

Office of Nuclear Reactor Regulation

U. S. Nuclear Regulatory Commission

Washington, D. C. 20555

13. TYPE OF REPORT

PE RIOD COVERED (Inclusive dares)

Technical

15. SUPPLEMENTARY NOTES

16. AOSTIAACT (200 words or less)

As a part of the Construction Permit (CP) review of the Clinch River Breeder Reactor Plant (CRBR), the Brookhaven National Laboratory was asked to compare the Design Basis Accidents that are considered in CRBR Preliminary Safety Analysis Report with those of the foreign contemporary plants (PHENIX, SUPER-PHENIX, SNR-300, PFR, and MONJU). A brief introductory review of any special or unusual characteristics of these plants is given. This is followed by discussions of the design basis accidents and their acceptance criteria. In spite of some discrepancies due either to semantics or to licensing decisions, there appears to be a considerable degree of unanimity in the selection (definition) of DBAs in all of these plants.

17. KEY WOROS ANO DCCURIENT ANALYSIS

17. DESCHArTORS

CRBR

LMFBR Design Basis Accident

CRBR Safety Analys is

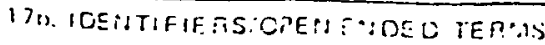

Urilinited

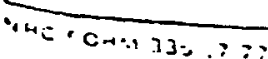

\begin{tabular}{|c|c|}
\hline 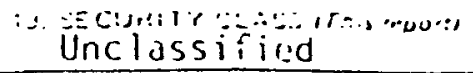 & $\because \because 0 \because=p \therefore . . . \mathrm{s}$ \\
\hline 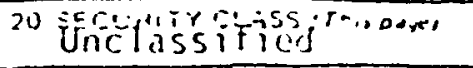 & 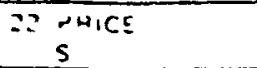 \\
\hline
\end{tabular}


WASHINGTON, D.C. 20555

OFFICIAL BUSINESS

PENALTY FOR PRIVATE USE, $\$ \mathbf{3 0 0}$

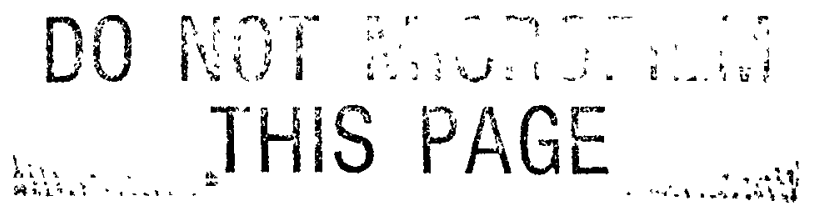

